\title{
Relaxation Time Correlation NMR for Mechanochemical in-situ Reaction Monitoring of Metal-Organic Frameworks
}

Madeleine E. Leger, ${ }^{a b}$ Jiangfeng Guo, ${ }^{b}$ Bryce MacMillan, ${ }^{b}$ Hatem M. Titi, ${ }^{c}$ Tomislav Friščić, ${ }^{c}$ Barry A. Blight, ${ }^{a *}$ and Bruce Balcom ${ }^{a, b *}$

${ }^{a}$ Department of Chemistry, University of New Brunswick, Fredericton, New Brunswick, E3B 5A3, Canada

${ }^{b}$ UNB MRI Centre, Department of Physics, University of New Brunswick, Fredericton, New Brunswick, E3B 5A3, Canada

${ }^{c}$ Department of Chemistry, McGill University, Montreal, Quebec, H3A 0B8, Canada

RECEIVED DATE (to be automatically inserted after your manuscript is accepted if required according to the journal that you are submitting your paper to)

*Corresponding author: bjb@unb.ca, b.blight@unb.ca 


\section{ABSTRACT:}

We present a new methodology for real-time observation of mechanochemical transformations, based on a magnetic resonance method in which $\mathrm{T}_{1}-\mathrm{T}_{2} *$ relaxation time correlation maps are used to track the formation of the popular metal-organic framework (MOF) materials Zn-MOF-74 and ZIF-8. This two-dimensional (2D) relaxation correlation measurement is a new method utilizing simple saturation recovery to obtain a $\mathrm{T}_{1}-\mathrm{T}_{2} *$ spectrum representing different hydrogen environments. The $2 \mathrm{D} \mathrm{T}_{1}-\mathrm{T}_{2} *$ results show a change in signal amplitudes, and their coordinates, within the plots as the reaction progresses, confirming reaction completion. Static solid samples are usually considered difficult to measure because of their short-lived $\mathrm{T}_{2} *$ signal and their common non-exponential decay. Using a new processing method, the signal from samples with non-exponential decay was quantified. The importance of key parameters such as the instrument deadtime, the recovery times, and magnetic field strength for the measurement of solids with a short-lived signal is established. This novel magnetic resonance measurement is important since it provides a simple and easy way to analyse an entire solid reaction mixture within its reaction vessel.

KEYWORDS: $\mathrm{T}_{1}-\mathrm{T}_{2}{ }^{*}$, nuclear magnetic resonance, relaxation time, saturation recovery, free induction decay, mechanochemistry, sinc-gaussian decay, metal-organic frameworks. 


\section{Introduction}

Mechanochemistry, i.e. chemical reactions induced and/or sustained through grinding, milling, shearing or other types of mechanical agitation, has emerged as a popular and highly versatile method for synthesizing molecules and materials in the absence of bulk solvents. ${ }^{1}$ The ability to circumvent the need for bulk solvents, at the same time providing access to chemical reactions that are fast, proceed at room temperature, and can provide access to molecules and materials challenging to obtain through other means, makes mechanochemistry a highly attractive and 'greener' alternative to more conventional solvent-based synthetic approaches. The scope of possible reactions by mechanochemical activation is widespread, with recent reviews and reports outlining mechanochemical approaches to organic, ${ }^{2,3}$ inorganic, ${ }^{4,5}$ organometallic, ${ }^{6}$ supramolecular, ${ }^{7-9}$ and coordination ${ }^{10,11}$ chemistry, as well as a range of advanced materials such as metal-organic frameworks, nanomaterials, and more. Mechanochemical transformations open the door to new synthetic opportunities ${ }^{12}$ such as the formation of unusual products, trapping of typically unstable intermediates, and the enhanced selectivity of products ${ }^{13}$ while also serving as an important tool for the reduction of reaction times. ${ }^{12}$

The mechanics of mechanochemical milling remain poorly understood, ${ }^{14,15}$ with attempts ${ }^{16,17}$ to elucidate the underlying physicochemical process often involving extensive and systematic investigations of temperature and pressure, including real-time approaches, as well as screening of milling frequency, sample-to-volume ratio, ball diameter, material of the milling assembly, presence and properties of liquid and/or polymer additives, and other parameters. ${ }^{12,18-21}$ It is noteworthy that in-depth and real-time monitoring of reactions by thermography, ${ }^{22-24}$ manometric studies, ${ }^{25}$ synchrotron powder X-ray diffraction (PXRD), ${ }^{26-30}$ Raman spectroscopy, ${ }^{21,31,32}$ and different combinations of these ${ }^{33-37}$ have shown great progress in our 
ability to monitor mechanochemical processes without the need to disrupt the reaction. Despite rapid and exciting successes, the in situ mechanochemistry monitoring approaches are still in their infancy with challenges yet to be overcome. One of these is the difficulty to obtain reliable insight into the course of mechanochemical reactions through acquiring data over a limited/small and inhomogeneous sampling area/volume, which can lead to low quality data that is difficult to interpret. ${ }^{38}$ Ex-situ monitoring continues to be an appropriate method for product analysis since the final product of a mechanochemical reaction is often stable and inert in nature. ${ }^{1}$

Magnetic resonance (MR) is an incredibly varied and expanding field. While it is best known for its uses in chemical spectroscopic analysis ${ }^{39,40}$ and in the medical field, ${ }^{41,42}$ MR can be used in many other capacities. Specifically, relaxation time experiments are currently used to analyse materials such as porous materials (e.g. rock cores) ${ }^{43-45}$ and foods. ${ }^{46-49}$ Most of these analyses involve the measurement of relaxation time parameters such as the longitudinal $\left(T_{1}\right)$ and transverse $\left(T_{2}\right)$ relaxation times. $T_{1}-T_{2}$ correlation analysis has proven to be a very important experiment in MR. The $T_{1}-T_{2}$ measurement is ideal for samples with long $T_{2}$ lifetimes. While this measurement is appropriate for a variety of samples, most solid materials have $\mathrm{T}_{2}$ values too shortlived to acquire useful data. Recently, Marreiros et al. ${ }^{50}$ published their work demonstrating MOF adsorption using $T_{1}-T_{2}$ measurements but have identified one of the core challenges to be measuring samples, such as solids, with short-lived $\mathrm{T}_{2}$ signal.

A new measurement utilizing $\mathrm{T}_{1}-\mathrm{T}_{2} *$ relaxation-time correlation maps reported by Enjilela et al. ${ }^{51}$ has great merit for solid samples. $\mathrm{T}_{2} *$ relaxation is driven by $\mathrm{T}_{2}$ relaxation which is typically very short in solid samples. The $T_{1}-T_{2} *$ method is simple and combines saturation recovery with free induction decays. The minimum observation time of the $\mathrm{T}_{1}-\mathrm{T}_{2} *$ method is only limited by the instrument deadtime, which makes it ideal to measure rigid samples with short $T_{2} *$ lifetimes. $T_{1}$ - 
$\mathrm{T}_{2} *$ measurements have been used to distinguish water and oil in shales, ${ }^{52,53}$ and to classify coal samples ${ }^{54}$ but they have yet been applied to monitor the development of solid-state chemical reactions.

In this work, we propose a novel approach for analysis of mechanochemical reactions in situ, using MR relaxation time correlation measurements to measure hydrogen environments of mechanochemical reactions. Our research provides a new and transformative method of analysis that will eliminate the need for material transfer, with all the attendant benefits. In such a scenario, the entire mechanochemical process, from synthesis to analysis, would take place in the milling container, with analysis being completed on the entire reaction mixture. Metal-organic frameworks $(\mathrm{MOFs})^{55-57}$ serve as ideal examples for the herein presented proof-of-principle study because of the significant changes in ligand conformation / topology and therefore, in hydrogen environment. Increasingly, mechanochemical synthesis is a popular method for MOF formation, ${ }^{58-65}$ with several MOFs already having been produced on a large scale by extrusion. ${ }^{66}$ In this work, we have used as a model system the synthesis of the well-known MOF material Zn-MOF-7467,68 (also known as $\mathrm{CPO}-27^{69,70}$ ), with special interest paid to the formation of a reaction intermediate and evident colour change. Also, an in-situ $\mathrm{T}_{1}-\mathrm{T}_{2}{ }^{*}$ relaxation correlation analysis method is successfully demonstrated using the mechanochemical synthesis of another popular MOF, the zeolitic imidazolate framework ZIF-8. ${ }^{67,71}$ 


\section{Experimental}

\subsection{Chemicals}

Zinc oxide (99\%), 2-methylimidazole (99\%), zinc acetate dihydrate (98\%), and 2,5dihydroxyterephthalic acid (98\%), were purchased from Sigma Aldrich. All reactants were used without further purification.

\subsection{MR method}

In solid-state time domain MR analysis, an instrument with a very short deadtime must be utilized to capture the short $\mathrm{T}_{2} *$ component found in solid materials. A 4.7 $\mathrm{T}$ vertical-bore superconducting magnet (Cryomagnetics) and a Redstone HF NMR spectrometer console (Tecmag) equipped with a Doty DS1-874 ${ }^{1} \mathrm{H}$ RF probe (Doty Scientific) were utilized. Samples were either transferred to a glass vial for analysis or kept in the lab-made Teflon jar used during milling (see Supporting Material (SM), section S1). A large amount of sample (gram scale) was required to acquire enough signal to overcome the background signal from the probe.

Parameters specific to these measurements included a dwell time of $400 \mathrm{~ns}$, a pulse length of $5 \mu \mathrm{s}$, a total of 8 scans, and the acquisition of 4096 time domain points for all samples. Some pulse specific parameters included a recycle delay of $175 \mathrm{~s}$ for the free induction decay (FID) sequence, and a set of 40 recovery times ranging from $15 \mu \mathrm{s}$ to $99 \mathrm{~s}$ for the saturation recovery pulse sequence. The receiver gain $(\mathrm{RG})$ depended on the intensity of signal measured from each sample and the values varied from 25 to 100 . The deadtime was $4 \mu \mathrm{s}$.

The data was collected using simple FID and saturation recovery (SM, section S1). Total measurement time took approximately 20 minutes for the individual FID measurement and 1 hour 48 minutes for the saturation recovery measurement. A MATLAB program employing code from 
the program by the Schlumberger-Doll Research Center was utilized to process the data to generate the $\mathrm{T}_{1}-\mathrm{T}_{2} *$ time correlation maps. This program assumed the signal change to be purely exponential. For non-exponential data processing, a new $\mathrm{T}_{1}-\mathrm{T}_{2} *$ analysis method was employed. ${ }^{72}$ A detailed explanation of the MR measurement is in the supplementary materials (SM, section S1).

\subsection{Synthetic methods and characterization}

The model mechanochemical preparation of Zn-MOF-74 and ZIF-8 followed the ball milling procedures previously established by Julien et al. ${ }^{30}$ and Beldon et al. ${ }^{73}$ respectively. For the mechanosynthesis of Zn-MOF-74, $6.67 \mathrm{mmol}$ of zinc oxide $(543 \mathrm{mg}$ ), $3.33 \mathrm{mmol}$ of 2,5dihydroxyterephthalic acid $(660 \mathrm{mg})$, and $0.75 \mathrm{~mL}$ of water were milled in a $15 \mathrm{~mL}$ polymethyl methacrylate (PMMA) jar for 90 minutes at $30 \mathrm{~Hz}$. For the milling synthesis of ZIF-8, $3.75 \mathrm{mmol}$ of zinc oxide (305 mg), $7.5 \mathrm{mmol}$ of 2-methylimidazole $(616 \mathrm{mg}$ ), and $0.2 \mu \mathrm{L} / \mathrm{mg}$ of N,Ndimethylformamide (DMF) $(175 \mu \mathrm{L})$ were added to a lab-made Teflon jar, with two big $10 \mathrm{~mm}$ zirconia balls. In a Retsch MM400 mixer mill, the jar was shaken at $30 \mathrm{~Hz}$ for 60 minutes.

The identities of the products were confirmed through powder X-ray diffraction (PXRD) patterns that were collected on a Bruker D2 PHASER diffractometer. The PXRD patterns of the solid reactants were obtained with a Bruker D8 Advance spectrometer. Thermogravimetric analysis (TGA) data was collected on a TGA 5500 Discovery instrument. Scanning Electron Microscope (SEM) images and Energy Dispersive X-ray Spectroscopy (EDS) data were collected on a JEOL JSM-6400 Scanning Electron Microscope equipped with an EDAX Genesis 4000 Energy Dispersive X-ray analyser. Detailed methodology for PXRD, TGA, SEM, and EDS can be found in the supplementary materials (SM, section S1). 


\section{Results and Discussion}

\subsection{Reactions and Characterization}

The mechanochemical syntheses of the two model MOFs by milling were analysed by MR relaxation time measurements. The synthesis of $\mathrm{Zn-MOF-74} \mathrm{followed} \mathrm{the} \mathrm{procedure} \mathrm{established}$ by Julien et al., ${ }^{30}$ consisting of liquid-assisted grinding (LAG) ${ }^{74} \mathrm{ZnO}, 2,5$-dihydroxyterephthalic acid, and water together. The material Zn-MOF-74 is a representative of the M-MOF-74 family of materials $(\mathrm{M}=\mathrm{a}$ divalent metal cation) which is particularly interesting for their excellent stability, as well as gas adsorption and catalysis abilities. ${ }^{75}$ The second model reaction involved the synthesis of ZIF-8 and followed the procedure previously shown by Beldon et al. ${ }^{73}$ which involved the LAG of $\mathrm{ZnO}$ and 2-methylimidazole in the presence of DMF as the liquid additive. The framework ZIF8 has been extensively studied for its promising capabilities in gas separation, sensing, and catalysis due to its excellent chemical and thermal stability. ${ }^{67}$ Detailed mechanisms of the mechanochemical syntheses of Zn-MOF- $74^{30}$ and ZIF- $8^{26,76}$ materials have been published. Th reaction mixtures were characterized by PXRD (SM, see section S5), SEM images and corresponding EDS data (SM, see section S6), TGA (SM, see section S7), as well as MR correlation plots.

\subsection{Mechanochemical synthesis of $\mathrm{Zn-MOF-74}$}

The formation of Zn-MOF-74 by mechanochemical milling is particularly interesting for its distinct colour changes and documented appearance of an intermediate. ${ }^{30}$ The use of clear PMMA milling jars permitted observation of these changes during reaction milling (Figure 1f). The starting mixture appears bright yellow due to the presence of 2,5-dihydroxyterephthalic acid ( $\left.\mathrm{H}_{4} \mathrm{dhta}\right)$, but it quickly transforms to a pale yellow, and eventually a white paste. White material is evidence of the intermediate, $\mathrm{Zn}\left(\mathrm{H}_{2} \mathrm{O}\right)_{2}\left(\mathrm{H}_{2} \mathrm{dhta}\right)$, being formed. The yellow hue of the $\mathrm{Zn}-\mathrm{MOF}$ - 
74 product is visible as the viscous mixture suddenly transforms into a powder, which is a sign of reaction completion. The final product is a dry dull yellow powder. The quick transition from liquid mixture to dry product is reminiscent of the observations made by the James group ${ }^{77}$ in organic mechanosynthesis and could be related to the moisture sequestration of $\mathrm{Zn}-\mathrm{MOF}-74 .^{78}$

Figure 1 demonstrates tracking of the progress of the Zn-MOF-74 mechanosynthesis using our new MR method. Distinct changes in the peaks are visible between the reactant, pre-milling, and after milling plots which is consistent with the formation of the targeted MOF product. Correlation plots of (a) zinc oxide and (b) 2,5-dihydroxyterephthalic acid were measured using different scaling to the other plots to account for low sample signal. The plots of (c) reactants pre-milling, (d) intermediate after 30 minutes of milling, and (e) Zn-MOF-74 as synthesized, all contained the
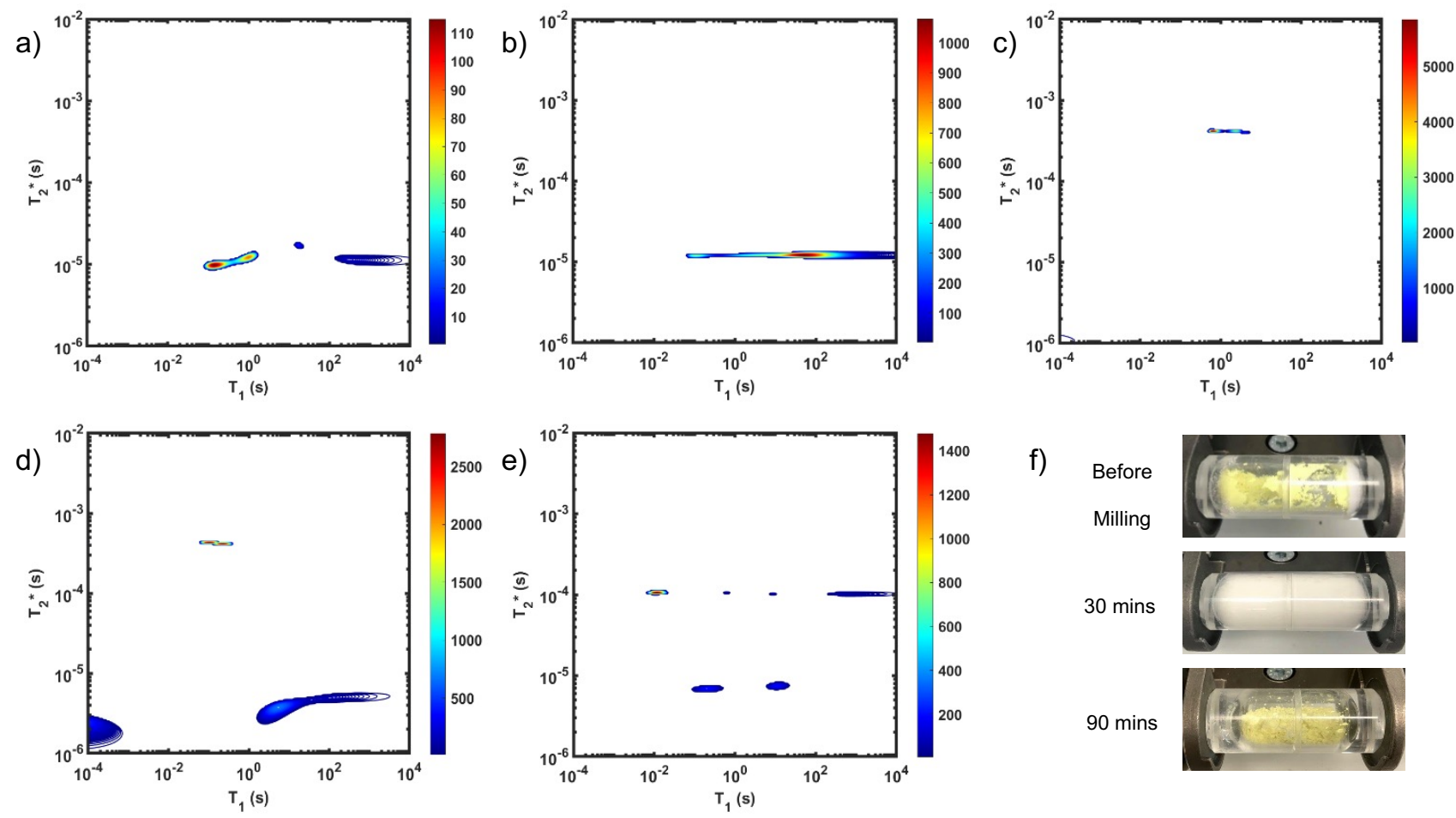

Figure 1: $\mathrm{T}_{1}-\mathrm{T}_{2} *$ correlation plots of (a) zinc oxide, (b) 2,5-dihydroxyterephthalic acid, (c) reactants pre-milling, (d) intermediate after 30 minutes of milling, and (e) Zn-MOF-74 as synthesized. In the (c) before milling plot, the lone intense peak corresponds to water signal which overpowers the signal of the other reagents because of its large quantity of hydrogen. Zinc oxide (a) only shows probe background signal. New peaks in the (e) after milling plot indicate the formation of ZnMOF-74. The (f) distinct colour changes from bright yellow, to white, to yellow, are evident. Scaling was adjusted to better reveal low signal. 
same amount of material and hydrogen, but loss of product did occur during transfer to the measurement vial. The plots show variable scaling to better reveal low signal.

The plot of zinc oxide contains no hydrogen signal, which is apparent in Figure 1a. Any observed signal can be ascribed to background signal from the probe, and possible minor impurities in the commercially sourced zinc oxide sample. The 2,5-dihydroxyterephthalic acid correlation plot (Figure 1b) shows a single short $\mathrm{T}_{2}{ }^{*}$ value at $12.1 \mu \mathrm{s}$. The $\mathrm{T}_{1}$ value at the center of the peak is at $47.7 \mathrm{~s}$ and the very left side of the peak is at $0.11 \mathrm{~s}$. The FID shows a clear sincgaussian decay (SM, see section S3).

The starting materials before milling include $0.75 \mathrm{~mL}$ of water, which is apparent in the $2 \mathrm{D}$ plot (Figure 1c). Water has long $\mathrm{T}_{1}$ and $\mathrm{T}_{2}$ lifetimes due to significant mobility in the liquid state. The noted intermediate was captured after 30 minutes of milling, shown in Figure 1d. The water peak is still very evident, with new peaks appearing in the bottom two corners of the plot. Formation of Zn-MOF-74 (Figure 1e) shows multiple new peaks, attributed to assembly of the periodic porous solid. The $T_{1}$ of the major peak on the upper left of the plot is at $12 \mathrm{~ms}$. The $T_{1}$ of the two peaks on the bottom are $0.20 \mathrm{~s}$ and $11.2 \mathrm{~s}$. While the $\mathrm{T}_{2}{ }^{*}$ values are $6.8 \mu \mathrm{s}, 7.6 \mu \mathrm{s}$ and 106 $\mu \mathrm{s}$. The smaller less intense peaks trailing off to the right at the longer $\mathrm{T}_{2}{ }^{*}$ are most likely artifacts. Water adsorption of the porous Zn-MOF-74 product explains the change in water peak. ${ }^{78}$ The relaxation time values for all these samples are summarized in table S1 in the supplementary information.

\subsection{Mechanochemical formation of ZIF-8 with in-situ MR Analysis}

The important advantage to highlight with the $T_{1}-T_{2} *$ MR measurement is the ability to complete in-situ analysis of the entire reaction mixture. This differs greatly from other in-situ 
methods, as X-rays or scattering lasers are limited to localized analysis. The synthesis of ZIF-8 served as our example (Figure 2). The reaction was milled in a small lab-made Teflon jar with two small zirconia balls. The materials, made from Teflon and zirconia, permitted the MR measurement due to low hydrogen content. This allows the reaction to be milled and analysed without ever having to open the milling vessel. The measurements of (a) zinc oxide and (b) 2methylimidazole employed a bigger sample than reaction scale to account for low sample signal. The plots of (c) reactants pre-milling, (d) ZIF-8 as synthesized and (e) ZIF-8 rinsed, all contained the same amount of material and therefore, hydrogen. The plots show variable scaling to better reveal low signal.
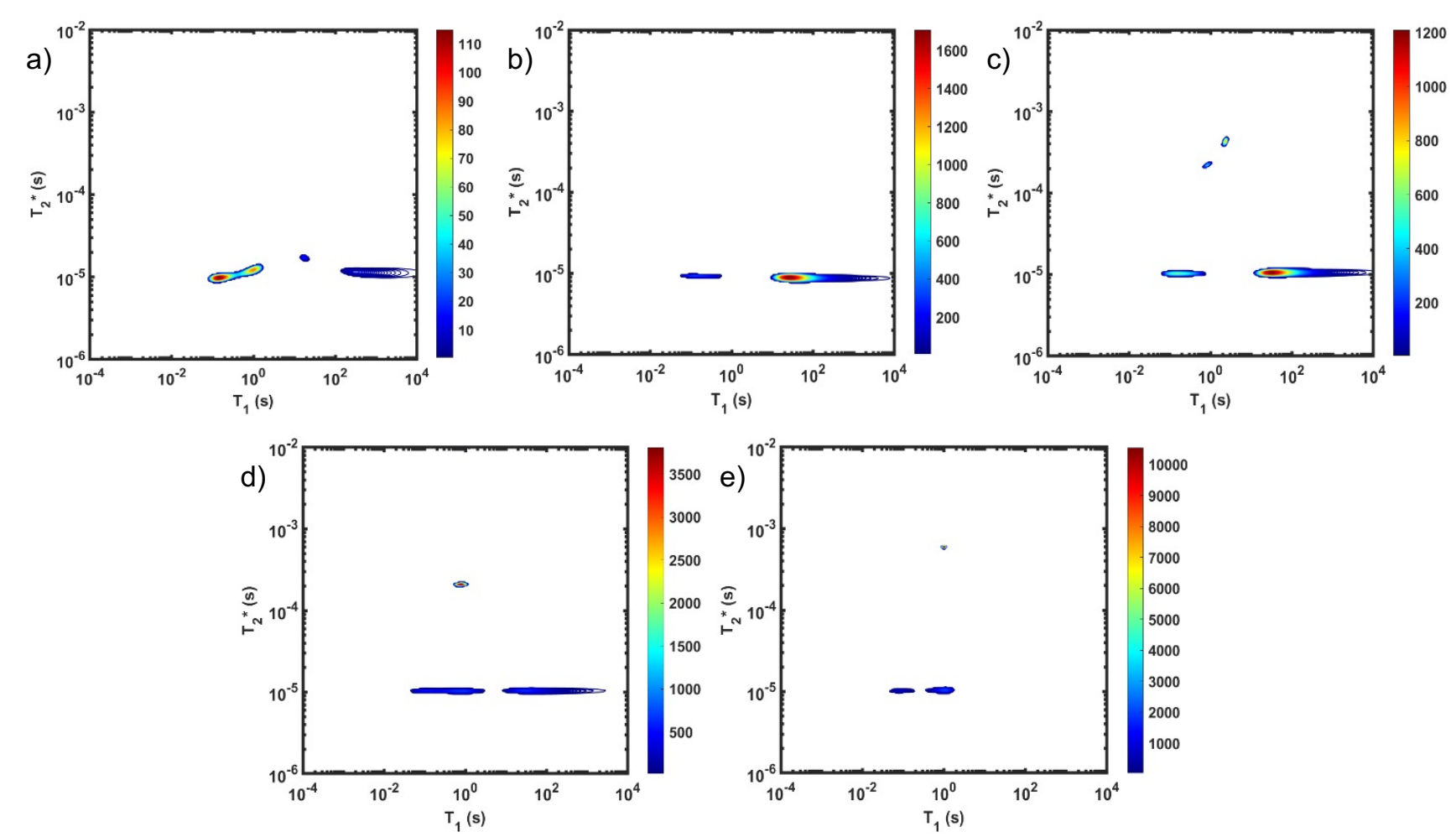

Figure 2. $\mathrm{T}_{1}-\mathrm{T}_{2} *$ correlation plots of (a) zinc oxide, (b) 2-methylimidazole, (c) reactants pre-milling, (d) ZIF-8 as-synthesized and (e) ZIF-8 rinsed. The plot of (c) pre-milling is very similar to the (b) 2-methylimidazole plot due to having more hydrogen from that reactant. The zinc oxide sample in (a) only shows probe background signal. Scaling was adjusted to better reveal low signal. 
As noted before, the zinc oxide signal (Figure 2a) consists mostly of background signal from the probe and vial. The 2-methylimidazole $2 \mathrm{D}$ plot (Figure $2 \mathrm{~b}$ ) indicates one short $\mathrm{T}_{2} *$ signal at $9.1 \mu \mathrm{s}$. The major peak has a $\mathrm{T}_{1}$ value of $24.9 \mathrm{~s}$. We posit that the smaller less intense peak with a $\mathrm{T}_{1}$ of $0.17 \mathrm{~s}$ comes from background signal. For 2-methylimidazole, the decay signal is sincgaussian (SM, see section S3).

Starting materials were mixed and spectra collected prior to milling (Figure 2c). It displays a very similar profile to 2-methylimidazole (Figure $2 \mathrm{~b}$ ), indicating that most of the hydrogen signal is coming from that reactant. The plot corresponding to the ZIF-8 product (Figure $2 \mathrm{~d}$ ) consists of three distinct peaks. The top intense peak has a $\mathrm{T}_{1}$ value of $0.78 \mathrm{~s}$ and $\mathrm{T}_{2} *$ of $210 \mu \mathrm{s}$, evidence of the DMF used to facilitate the reaction and molecular water formed as a by-product. The ZIF-8 peak just underneath it has a similar $\mathrm{T}_{1}$ value of $0.83 \mathrm{~s}$ and a shorter $\mathrm{T}_{2} *$ of $10.5 \mu \mathrm{s}$. The third peak with a short $\mathrm{T}_{2} *$ value of $10.5 \mu \mathrm{s}$ but longer $\mathrm{T}_{1}$ value of $28.8 \mathrm{~s}$ represents leftover 2methylimidazole. This is supported by figure $2 \mathrm{e}$, which shows the product after rinsing and drying overnight under vacuum where the 2 -methylimidazole peak is absent. The remaining signal has similar relaxation time values as the previous plot. The relaxation time values for all these samples are summarized in Table $\mathrm{S} 1$ in the supplementary materials. It is worth noting that some $\mathrm{ZnO}$ phase does remain in the mixture, and though MR inactive, is visible in the PXRD.

\subsection{Exponential vs non-exponential analysis}

Two types of processing exist for $\mathrm{T}_{1}-\mathrm{T}_{2} *$ data sets. First, the simpler and best-known option is to process all the data as if the magnetization evolution curves are all exponentials. This type of processing is simple and is commonly used, and the MATLAB program is already developed by the Schlumberger-Doll Research Center. The program is user-friendly and only requires a few parameters to be manually changed. We utilized this method to process the results in figures 1 and 
2. The disadvantage is that many rigid samples, like many of our solid samples, display nonexponential gaussian or sinc-gaussian $\mathrm{T}_{2} *$ decay curves (SM, see section $\left.\mathrm{S} 3\right) .{ }^{79}$ The sinc-gaussian non-exponential $\mathrm{T}_{2} *$ decay in the time domain occurs due to a distribution of Pake doublets in the frequency domain..$^{80}$

This results in non-exponential curves being processed as exponential curves. Although this can be an issue for quantification, the results shown by Guo et al. demonstrate that the plots using this approximation yield similar relaxation time values to the non-exponential processing results. ${ }^{72}$ Exponential processing is a suitable method for species identification and differentiation, but it is not suitable for quantification of the samples. This is further supported in figure 3 where we compare exponential and non-exponential processing of ZIF-8 synthesis where the exponential processing peaks are very similar to the graphs generated from the non-exponential processing method (SM, see section S4).

Non-exponential processing is vital for quantifying signal intensity by its accurate fitting of gaussian or sinc-gaussian curves. A novel processing method reported by Guo et al. processes the non-exponential part of the decay and the exponential part separately to generate the correlation plots to achieve accurate quantifiable results of non-exponential decays, or a combination of exponential and non-exponential decays..$^{72} \mathrm{MR}$ measurements are linear measurements and can be demonstrated as such. In our study, the hydrogen signal of materials before milling and after milling is conserved as established in both of our MOF reactions milled in our lab-made Teflon jars. The synthesis of ZIF-8 and its conservation of signal is demonstrated in figure 3.

Figure $3 \mathrm{a}$ and $3 \mathrm{~b}$ demonstrate the correlation plot results using exponential decay processing while figure 3a-f demonstrate results using non-exponential processing. As mentioned previously, the resulting relaxation time values between the two types of processing methods are very similar 
but, without non-exponential processing, accurate quantification of the samples is impossible. Figure 3 compares the two methods. In the pre-milling figures $3 \mathrm{a}$ and $3 \mathrm{c}$, the most intense peak is located at a $\mathrm{T}_{1}$ of $30.9 \mathrm{~s}$ for exponential processing and $28.8 \mathrm{~s}$ for the non-exponential processing. The $\mathrm{T}_{2}{ }^{*}$ is the same at $10.5 \mu \mathrm{s}$ for both types of processing. In the post-milling figures $3 \mathrm{~b}$ and $3 \mathrm{~d}$, the liquid peak at a longer $\mathrm{T}_{2} *$ is situated at $0.78 \mathrm{~s}$ and $210 \mu \mathrm{s}$ for both types of processing, for $\mathrm{T}_{1}$ and $\mathrm{T}_{2} *$ respectively. The ZIF-8 peak, at the shortest $\mathrm{T}_{1}$ and $\mathrm{T}_{2} *$ values, has a $\mathrm{T}_{1}$ of $0.83 \mathrm{~s}$ and $\mathrm{T}_{2} *$ of $10.5 \mu \mathrm{s}$ for exponential and a $\mathrm{T}_{1}$ of $0.90 \mathrm{~s}$ and $\mathrm{T}_{2} *$ of $20.0 \mu \mathrm{s}$ for non-exponential processing. The third peak corresponds to leftover 2-methylimidazole. The relaxation times are summarized in table S2 of the supplementary information.

The easiest and most accurate method for quantification involves the back-extrapolation of 1D $\mathrm{T}_{2} *$ data sets obtained by FID to obtain the time-zero value intensity (figure $3 \mathrm{e}$ and $3 \mathrm{f}$ ). In this case, the decay of pre-milling and ZIF-8 as synthesized both contain a gaussian component and an exponential component. In these FID plots, the black line represents the raw data while the red line indicates the fitting. The reactants pre-milling has a signal intensity of $9.10 \times 10^{4}$ and the ZIF-8 as synthesized of $9.69 \times 10^{4}$, establishing conservation of hydrogen signal before and after milling. The 2D plots processed by non-exponential fitting can also be used to calculate total signal intensity (figure $3 \mathrm{c}$ and $3 \mathrm{~d}$ ). Using this method, the pre-milling has a signal intensity of $9.70 \times 10^{4}$ and the ZIF- 8 as synthesized of $1.05 \times 10^{5}$. The values are still similar enough to conclude a linear measurement, but the signal intensity determined from the FID data will always be more accurate. 


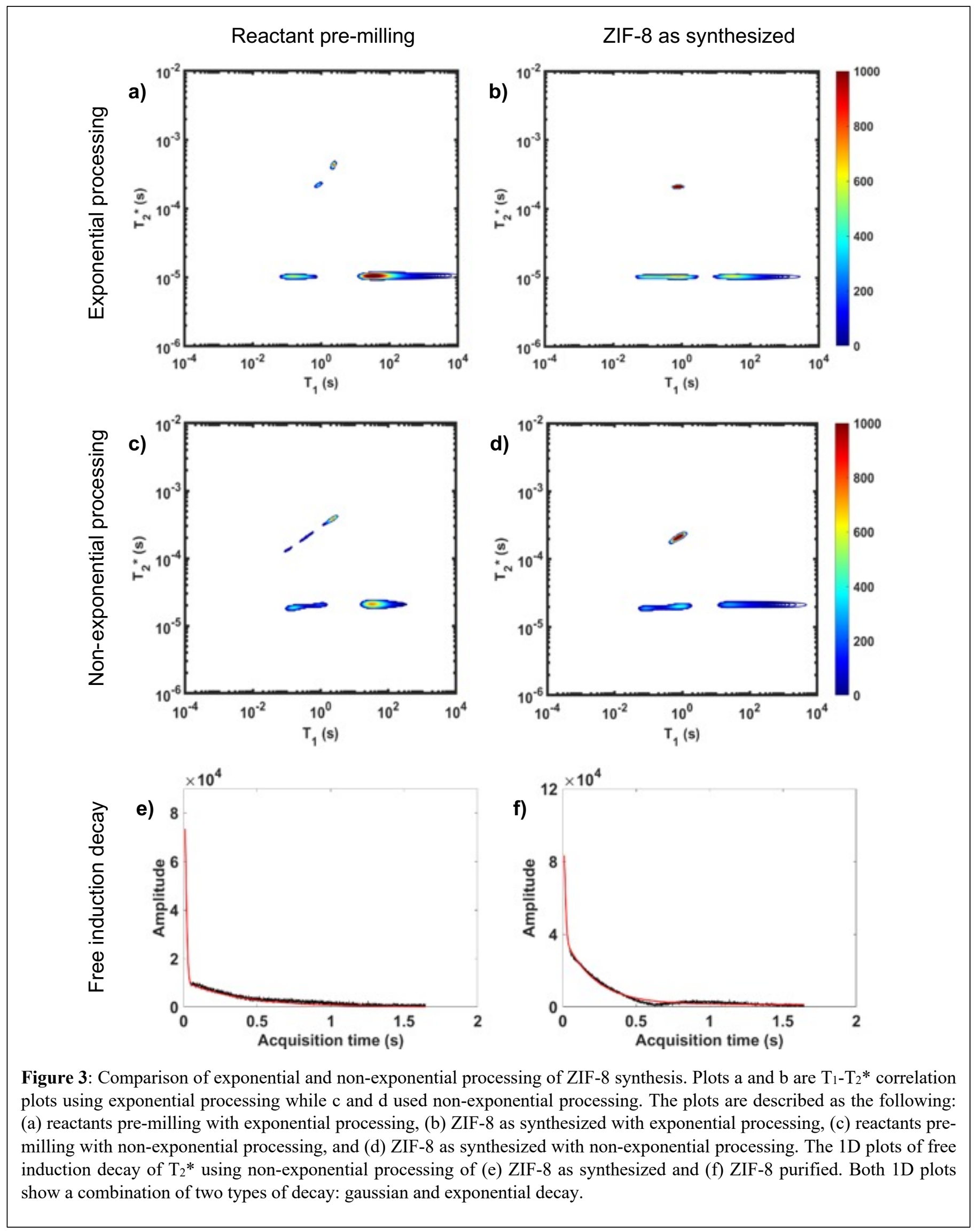




\section{Conclusions}

We describe for the first time, a new method of in-situ solid-state analysis of mechanochemical reactions using $\mathrm{T}_{1}-\mathrm{T}_{2} *$ relaxation correlation plots, where whole-reaction mixtures can be evaluated in the reaction vessel by readily available short deadtime MR equipment. Simple saturation recovery sequence was employed to acquire $\mathrm{T}_{1}-\mathrm{T}_{2} *$ data from the solid samples. A short instrument deadtime and long recovery times were needed to acquire the short-lived signal and capture the long $\mathrm{T}_{1}$ values. The reactions of Zn-MOF-74 and ZIF-8 were completed in a ball mill and monitored using $\mathrm{T}_{1}-\mathrm{T}_{2} *$ correlation maps. Significant differences in relaxation correlation peaks were used to determine the completion of the reaction, confirmed by PXRD data and TGA. The $\mathrm{T}_{1}-\mathrm{T}_{2}{ }^{*}$ measurement provides an easy, versatile, and solvent-free process especially useful for mechanochemical reactions and other chemical transformations, such as the formation of aggregates for example. This new method can ultimately be applied to many industrial processes and materials, as already seen with shales and coals. ${ }^{52-54}$ Moving forward, we envisage the use of an economical lower-field benchtop NMR instrument that will allow the measurement to be shorter, more accessible, and more versatile without the need for specially engineered equipment for data collection. $T_{1}$ is greatly influenced by magnetic field, and a lower field magnet would shorten the $\mathrm{T}_{1}$, therefore shortening the measurement time greatly. The analysis method will be further improved by shortening the measurement time by utilising a Look Locker sequence. This would permit the acquisition of multiple FIDs per saturation, instead of only acquiring one FID per saturation using our current saturation recovery measurement. A probe without background signal would be helpful and allow the measurement of smaller scale reactions with less hydrogen content. To expand the scope of the measurement, we are now exploring $\mathrm{T}_{1 \rho^{-}}$ $\mathrm{T}_{2}{ }^{*}$ correlation measurements. ${ }^{72}$ 


\section{References}

(1) James, S. L.; Adams, C. J.; Bolm, C.; Braga, D.; Collier, P.; Friščić, T.; Grepioni, F.; Harris, K. D. M.; Hyett, G.; Jones, W.; Krebs, A.; Mack, J.; Maini, L.; Orpen, A. G.; Parkin, I. P.; Shearouse, W. C.; Steed, J. W.; Waddell, D. C. Mechanochemistry: Opportunities for New and Cleaner Synthesis. Chem. Soc. Rev. 2012, 41 (1), 413-447. https://doi.org/10.1039/C1CS15171A.

(2) Tan, D.; Friščić, T. Mechanochemistry for Organic Chemists: An Update. Euro. J. Org. Chem. 2018, 2018 (1), 18-33. https://doi.org/10.1002/ejoc.201700961.

(3) Egorov, I. N.; Santra, S.; Kopchuk, D. S.; Kovalev, I. S.; Zyryanov, G. v.; Majee, A.; Ranu, B. C.; Rusinov, V. L.; Chupakhin, O. N. Ball Milling: An Efficient and Green Approach for Asymmetric Organic Syntheses. Green Chem. 2020, 22 (2), 302-315. https://doi.org/10.1039/c9gc03414e.

(4) Tan, D.; Garcí, F. Main Group Mechanochemistry: From Curiosity to Established Protocols. Chem. Soc. Rev. 2019, 48 (8), 2274-2292. https://doi.org/10.1039/c7cs00813a.

(5) Moores, A. Bottom up, Solid-Phase Syntheses of Inorganic Nanomaterials by Mechanochemistry and Aging. Curr. Opin. Green Sust. Chem. 2018, 12, 33-37. https://doi.org/10.1016/j.cogsc.2018.05.004.

(6) Rightmire, N. R.; Hanusa, T. P. Advances in Organometallic Synthesis with Mechanochemical Methods. Dalton Trans. 2016, 45 (6), 2352-2362. https://doi.org/10.1039/c5dt03866a.

(7) Braga, D.; Maini, L.; Grepioni, F. Mechanochemical Preparation of Co-Crystals. Chem. Soc. Rev. 2013, 42 (18), 7638-7648. https://doi.org/10.1039/c3cs60014a.

(8) Bose, A.; Mal, P. Mechanochemistry of Supramolecules. Beilstein J. Org. Chem. 2019, 15, 881900. https://doi.org/10.3762/bjoc.15.86.

(9) Friščić, T. Supramolecular Concepts and New Techniques in Mechanochemistry: Cocrystals, Cages, Rotaxanes, Open Metal-Organic Frameworks. Chem. Soc. Rev. 2012, 41 (9), 3493-3510. https://doi.org/10.1039/c2cs15332g.

(10) Mottillo, C.; Friščić, T. Advances in Solid-State Transformations of Coordination Bonds: From the Ball Mill to the Aging Chamber. Molecules 2017, 22 (1).

https://doi.org/10.3390/molecules22010144.

(11) Friščić, T.; Halasz, I.; Štrukil, V.; Eckert-Maksić, M.; Dinnebier, R. E. Clean and Efficient Synthesis Using Mechanochemistry: Coordination Polymers, Metal-Organic Frameworks and Metallodrugs. Croat. Chem. Acta 2012, 85 (3), 367-378. https://doi.org/10.5562/cca2014.

(12) Howard, J. L.; Cao, Q.; Browne, D. L. Mechanochemistry as an Emerging Tool for Molecular Synthesis: What Can It Offer? Chem. Sci. 2018, 9 (12), 3080-3094.

https://doi.org/10.1039/c7sc05371a.

(13) Hernández, J. G.; Bolm, C. Altering Product Selectivity by Mechanochemistry. J. of Org. Chem. 2017, 82 (8), 4007-4019. https://doi.org/10.1021/acs.joc.6b02887. 
(14) Užarević, K.; Halasz, I.; Friščić, T. Real-Time and in Situ Monitoring of Mechanochemical Reactions: A New Playground for All Chemists. Journal of Physical Chemistry Letters 2015, 6 (20), 4129-4140. https://doi.org/10.1021/acs.jpclett.5b01837.

(15) Colacino, E.; Carta, M.; Pia, G.; Porcheddu, A.; Ricci, P. C.; Delogu, F. Processing and Investigation Methods in Mechanochemical Kinetics. ACS Omega 2018, 3 (8), 9196-9209.

https://doi.org/10.1021/ACSOMEGA.8B01431.

(16) Michalchuk, A. A. L.; Tumanov, I. A.; Drebushchak, V. A.; Boldyreva, E. v. Advances in Elucidating Mechanochemical Complexities via Implementation of a Simple Organic System. Faraday Discuss. 2014, 170, 311-335. https://doi.org/10.1039/c3fd00150d.

(17) McKissic, K. S.; Caruso, J. T.; Blair, R. G.; Mack, J. Comparison of Shaking versus Baking: Further Understanding the Energetics of a Mechanochemical Reaction. Green Chem. 2014, 16 (3), 16281632. https://doi.org/10.1039/c3gc41496e.

(18) Schmidt, R.; Burmeister, C. F.; Baláž, M.; Kwade, A.; Stolle, A. Effect of Reaction Parameters on the Synthesis of 5-Arylidene Barbituric Acid Derivatives in Ball Mills. Organic Process Research \& Development 2015, 19 (3), 427-436. https://doi.org/10.1021/op5003787.

(19) Schmidt, R.; Scholze, • H Martin; Stolle, • Achim. Temperature Progression in a Mixer Ball Mill. International Journal of Industrial Chemistry 2016, 7, 181-186. https://doi.org/10.1007/s40090016-0078-8.

(20) Stolle, A.; Schmidt, R.; Jacob, K. Scale-up of Organic Reactions in Ball Mills: Process Intensification with Regard to Energy Efficiency and Economy of Scale. Faraday Discussions 2014, 170, 267-286. https://doi.org/10.1039/c3fd00144j.

(21) Julien, P. A.; Malvestiti, I.; Friščić, T. The Effect of Milling Frequency on a Mechanochemical Organic Reaction Monitored by in Situ Raman Spectroscopy. Beilstein Journal of Organic Chemistry 2017, 13, 2160-2168. https://doi.org/10.3762/bjoc.13.216.

(22) You, S.; Chen, M.-W.; Dlott, D. D.; Suslick, K. S. Ultrasonic Hammer Produces Hot Spots in Solids. Nature Comm. 2015, 6 (1), 1-7. https://doi.org/10.1038/ncomms7581.

(23) Deidda, C.; Delogu, F.; Cocco, G. In Situ Characterisation of Mechanically-Induced SelfPropagating Reactions. Journal of Materials Science 2004 39:16 2004, 39 (16), 5315-5318. https://doi.org/10.1023/B:JMSC.0000039236.48464.8F.

(24) McKissic, K. S.; Caruso, J. T.; Blair, R. G.; Mack, J. Comparison of Shaking versus Baking: Further Understanding the Energetics of a Mechanochemical Reaction. Green Chem. 2014, 16 (3), 16281632. https://doi.org/10.1039/C3GC41496E.

(25) Brekalo, I.; Yuan, W.; Mottillo, C.; Lu, Y.; Zhang, Y.; Casaban, J.; Holman, K. T.; James, S. L.; Duarte, F.; Williams, P. A.; Harris, K. D. M.; Friščić, T. Manometric Real-Time Studies of the Mechanochemical Synthesis of Zeolitic Imidazolate Frameworks. Chem. Sci. 2020, 11 (8), 21412147. https://doi.org/10.1039/C9SC05514B.

(26) Halasz, I.; Kimber, S. A. J.; Beldon, P. J.; Belenguer, A. M.; Adams, F.; Honkimäki, V.; Nightingale, R. C.; Dinnebier, R. E.; Friščić, T. In Situ and Real-Time Monitoring of Mechanochemical Milling 
Reactions Using Synchrotron X-Ray Diffraction. Nature Protocols 2013, 8 (9), 1718-1729. https://doi.org/10.1038/nprot.2013.100.

(27) Friščić, T.; Halasz, I.; Beldon, P. J.; Belenguer, A. M.; Adams, F.; Kimber, S. A. J.; Honkimäki, V.; Dinnebier, R. E. Real-Time and in Situ Monitoring of Mechanochemical Milling Reactions. Nature Chemistry 2013, 5 (1), 66-73. https://doi.org/10.1038/nchem.1505.

(28) Oliveira, P. F. M. de; Michalchuk, A. A. L.; Buzanich, A. G.; Bienert, R.; Torresi, R. M.; Camargo, P. H. C.; Emmerling, F. Tandem X-Ray Absorption Spectroscopy and Scattering for in Situ TimeResolved Monitoring of Gold Nanoparticle Mechanosynthesis. Chemical Comm. 2020, 56 (71), 10329-10332. https://doi.org/10.1039/D0CC03862H.

(29) Katsenis, A. D.; Puškarić, A.; Štrukil, V.; Mottillo, C.; Julien, P. A.; Užarević, K.; Pham, M. H.; Do, T. O.; Kimber, S. A. J.; Lazić, P.; Magdysyuk, O.; Dinnebier, R. E.; Halasz, I.; Friščić, T. In Situ X-Ray Diffraction Monitoring of a Mechanochemical Reaction Reveals a Unique Topology Metal-Organic Framework. Nature Comm. 2015, 6. https://doi.org/10.1038/ncomms7662.

(30) Julien, P. A.; Užarević, K.; Katsenis, A. D.; Kimber, S. A. J.; Wang, T.; Farha, O. K.; Zhang, Y.; Casaban, J.; Germann, L. S.; Etter, M.; Dinnebier, R. E.; James, S. L.; Halasz, I.; Friščić, T. In Situ Monitoring and Mechanism of the Mechanochemical Formation of a Microporous MOF-74 Framework. J. Am. Chem. Soc. 2016, 138 (9), 2929-2932. https://doi.org/10.1021/jacs.5b13038.

(31) Gracin, D.; Štrukil, V.; Friščic̈, T.; Halasz, I.; Užarevï̈, K. Laboratory Real-Time and in Situ Monitoring of Mechanochemical Milling Reactions by Raman Spectroscopy. Angewandte Chemie - International Edition 2014, 53 (24), 6193-6197. https://doi.org/10.1002/anie.201402334.

(32) Lukin, S.; Užarević, K.; Halasz, I. Raman Spectroscopy for Real-Time and in Situ Monitoring of Mechanochemical Milling Reactions. Nat. Protoc. 2021, 16 (7), 3492-3521. https://doi.org/10.1038/s41596-021-00545-x.

(33) Batzdorf, L.; Fischer, F.; Wilke, M.; Wenzel, K. J.; Emmerling, F. Direct in Situ Investigation of Milling Reactions Using Combined X-Ray Diffraction and Raman Spectroscopy. Angewandte Chemie - International Edition 2015, 54 (6), 1799-1802. https://doi.org/10.1002/anie.201409834.

(34) Kulla, H.; Haferkamp, S.; Akhmetova, I.; Röllig, M.; Maierhofer, C.; Rademann, K.; Emmerling, F. In Situ Investigations of Mechanochemical One-Pot Syntheses. Angew. Chem. Int. Ed. 2018, 57 (20), 5930-5933. https://doi.org/10.1002/ANIE.201800147.

(35) Julien, P. A.; Germann, L. S.; Titi, H. M.; Etter, M.; Dinnebier, R. E.; Sharma, L.; Baltrusaitis, J.; Friščić, T. In Situ Monitoring of Mechanochemical Synthesis of Calcium Urea Phosphate Fertilizer Cocrystal Reveals Highly Effective Water-Based Autocatalysis. Chem. Sci. 2020, 11 (9), 23502355. https://doi.org/10.1039/C9SC06224F.

(36) Kulla, H.; Wilke, M.; Fischer, F.; Röllig, M.; Maierhofer, C.; Emmerling, F. Warming up for Mechanosynthesis - Temperature Development in Ball Mills during Synthesis. Chem. Comm. 2017, 53 (10), 1664-1667. https://doi.org/10.1039/C6CC08950J.

(37) Užarević, K.; Štrukil, V.; Mottillo, C.; Julien, P. A.; Puškarić, A.; Friščić, T.; Halasz, I. Exploring the Effect of Temperature on a Mechanochemical Reaction by in Situ Synchrotron Powder X-Ray 
Diffraction. Cryst. Growth Des. 2016, 16 (4), 2342-2347.

https://doi.org/10.1021/ACS.CGD.6B00137.

(38) Michalchuk, A. A. L.; Tumanov, I. A.; Konar, S.; Kimber, S. A. J.; Pulham, C. R.; Boldyreva, E. v. Challenges of Mechanochemistry: Is In Situ Real-Time Quantitative Phase Analysis Always Reliable? A Case Study of Organic Salt Formation. Adv. Sci. 2017, 4 (9), 1700132. https://doi.org/10.1002/advs.201700132.

(39) Singh, K.; Blümich, B. NMR Spectroscopy with Compact Instruments. TrAC - Trends Anal. Chem. 2016, 83, 12-26. https://doi.org/10.1016/j.trac.2016.02.014.

(40) Brown, S. P. Applications of High-Resolution 1H Solid-State NMR. Solid State Nucl. Magn. Reson. 2011, 41, 1-27. https://doi.org/10.1016/j.ssnmr.2011.11.006.

(41) Taylor, A. J.; Salerno, M.; Dharmakumar, R.; Jerosch-Herold, M. T1 Mapping Basic Techniques and Clinical Applications. JACC: Cardiovasc. Imaging 2016, 9, 67-81. https://doi.org/10.1016/j.jcmg.2015.11.005.

(42) Dong, Z.; Andrews, T.; Xie, C.; Yokoo, T. Advances in MRI Techniques and Applications. BioMed Res. Int. 2015, 2015, 1-2. https://doi.org/10.1155/2015/139043.

(43) Mitchell, J.; Chandrasekera, T. C.; Holland, D. J.; Gladden, L. F.; Fordham, E. J. Magnetic Resonance Imaging in Laboratory Petrophysical Core Analysis. Phys. Rep. 2013, 526 (3), 165-225. https://doi.org/10.1016/j.physrep.2013.01.003.

(44) Coates, G. R.; Xiao, L.; Prammer, M. G. NMR Logging Principles and Applications, 1st ed.; Halliburton Energy Services, Ed.; Gulf Publishing Company: Houston, 1999.

(45) Chen, Q.; Marble, A. E.; Colpitts, B. G.; Balcom, B. J. The Internal Magnetic Field Distribution, and Single Exponential Magnetic Resonance Free Induction Decay, in Rocks. J. Magn. Reson. 2005, 175 (2), 300-308. https://doi.org/10.1016/j.jmr.2005.05.001.

(46) Marangoni, A. G.; Macmillan, B.; Marty, S.; Balcom, B. J. Spatial Mapping of Solid and Liquid Lipid in Chocolate. In Magn. Res. Food Sci.; 2009; pp 105-112.

(47) Hemdane, S.; Jacobs, P. J.; Bosmans, G. M.; Verspreet, J.; Delcour, J. A.; Courtin, C. M. Study of Biopolymer Mobility and Water Dynamics in Wheat Bran Using Time-Domain $1 \mathrm{H}$ NMR Relaxometry. Food Chem. 2017, 236, 68-75. https://doi.org/10.1016/j.foodchem.2017.01.020.

(48) Troutman, M. Y.; Mastikhin, I. v.; Balcom, B. J.; Eads, T. M.; Ziegler, G. R. Moisture Migration in Soft-Panned Confections during Engrossing and Aging as Observed by Magnetic Resonance Imaging. J. Food Eng. 2001, 48 (3), 257-267. https://doi.org/10.1016/S0260-8774(00)00167-9.

(49) Mariette, F. Investigations of Food Colloids by NMR and MRI. Curr. Opin. Colloid Interface Sci. 2009, 14 (3), 203-211. https://doi.org/10.1016/j.cocis.2008.10.006.

(50) Marreiros, J. O.; de Oliveira-Silva, R.; lacomi, P.; Llewellyn, P. L.; Ameloot, R.; Sakellariou, D. Benchtop In Situ Measurement of Full Adsorption Isotherms by NMR. J. Am. Chem. Soc 2021, 143, 8249-8254. https://doi.org/10.1021/jacs.1c03716. 
(51) Enjilela, R.; Guo, J.; MacMillan, B.; Marica, F.; Afrough, A.; Balcom, B. T1-T2* Relaxation Correlation Measurements. J. Magn. Res. 2021, 326, 106961.

https://doi.org/10.1016/j.jmr.2021.106961.

(52) Zamiri, M. S.; MacMillan, B.; Marica, F.; Guo, J.; Romero-Zerón, L.; Balcom, B. J. Petrophysical and Geochemical Evaluation of Shales Using Magnetic Resonance T1-T2* Relaxation Correlation. Fuel 2021, 284, 119014. https://doi.org/10.1016/j.fuel.2020.119014.

(53) Zamiri, M. S.; Florea, M.; Romero-Zerón, L.; Balcom, B. J. Monitoring Shale Water Uptake Using 2D Magnetic Resonance Relaxation Correlation and SPRITE MRI. Chem. Eng. J. 2021, 428, 131042undefined. https://doi.org/https://doi.org/10.1016/j.cej.2021.131042.

(54) Guo, J.; Macmillan, B.; Sadegh Zamiri, M.; Balcom, B. J. Two Dimensional 1 H Magnetic Resonance Relaxometry-Based Analyses of Argonne Premium Coals. Fuel 2021, 302, 121106.

https://doi.org/10.1016/j.fuel.2021.121106.

(55) Zhou, H.-C.; Long, J. R.; Yaghi, O. M. Introduction to Metal-Organic Frameworks. Chem. Rev. 2012, 112 (2), 673-674. https://doi.org/10.1021/CR300014X.

(56) Furukawa, H.; Cordova, K. E.; O’Keeffe, M.; Yaghi, O. M. The Chemistry and Applications of MetalOrganic Frameworks. Science 2013, 341 (6149). https://doi.org/10.1126/SCIENCE.1230444.

(57) Yuan, S.; Feng, L.; Wang, K.; Pang, J.; Bosch, M.; Lollar, C.; Sun, Y.; Qin, J.; Yang, X.; Zhang, P.; Wang, Q.; Zou, L.; Zhang, Y.; Zhang, L.; Fang, Y.; Li, J.; Zhou, H.-C. Stable Metal-Organic Frameworks: Design, Synthesis, and Applications. Adv. Mater. 2018, 30 (37), 1704303. https://doi.org/10.1002/ADMA.201704303.

(58) Friščić, T.; Reid, D. G.; Halasz, I.; Stein, R. S.; Dinnebier, R. E.; Duer, M. J. Ion- and Liquid-Assisted Grinding: Improved Mechanochemical Synthesis of Metal-Organic Frameworks Reveals Salt Inclusion and Anion Templating. Angew. Chem. Int. Ed. 2010, 49 (4), 712-715. https://doi.org/10.1002/ANIE.200906583.

(59) Głowniak, S.; Szczęśniak, B.; Choma, J.; Jaroniec, M. Mechanochemistry: Toward Green Synthesis of Metal-Organic Frameworks. Mater. Today 2021, 46, 109-124.

https://doi.org/10.1016/J.MATTOD.2021.01.008.

(60) Stolar, T.; Užarević, K. Mechanochemistry: An Efficient and Versatile Toolbox for Synthesis, Transformation, and Functionalization of Porous Metal-Organic Frameworks. CrystEngComm 2020, 22 (27), 4511-4525. https://doi.org/10.1039/D0CE00091D.

(61) Pichon, A.; Lazuen-Garay, A.; James, S. L. Solvent-Free Synthesis of a Microporous Metal-Organic Framework. CrystEngComm 2006, 8 (3), 211-214. https://doi.org/10.1039/B513750K.

(62) Garay, A. L.; Pichon, A.; James, S. L. Solvent-Free Synthesis of Metal Complexes. Chem. Soc. Rev. 2007, 36 (6), 846-855. https://doi.org/10.1039/B600363J.

(63) Ma, X.; Yuan, W.; Bell, S. E. J.; James, S. L. Better Understanding of Mechanochemical Reactions: Raman Monitoring Reveals Surprisingly Simple 'Pseudo-Fluid' Model for a Ball Milling Reaction. Chem. Comm. 2014, 50 (13), 1585-1587. https://doi.org/10.1039/C3CC47898J. 
(64) Aboutorabi, L.; Morsali, A. Structural Transformations and Solid-State Reactivity Involving Nano Lead(II) Coordination Polymers via Thermal, Mechanochemical and Photochemical Approaches. Coord. Chem. Rev. 2016, 310, 116-130. https://doi.org/10.1016/J.CCR.2015.10.006.

(65) Fujii, K.; Garay, A. L.; Hill, J.; Sbircea, E.; Pan, Z.; Xu, M.; Apperley, D. C.; James, S. L.; Harris, K. D. M. Direct Structure Elucidation by Powder X-Ray Diffraction of a Metal-Organic Framework Material Prepared by Solvent-Free Grinding. Chem. Comm. 2010, 46 (40), 7572-7574. https://doi.org/10.1039/C0CC02635B.

(66) Crawford, D.; Casaban, J.; Haydon, R.; Giri, N.; McNally, T.; James, S. L. Synthesis by Extrusion: Continuous, Large-Scale Preparation of MOFs Using Little or No Solvent. Chem. Sci. 2015, 6 (3), 1645-1649. https://doi.org/10.1039/C4SC03217A.

(67) Park, K. S.; Ni, Z.; Côté, A. P.; Choi, J. Y.; Huang, R.; Uribe-Romo, F. J.; Chae, H. K.; O’Keeffe, M.; Yaghi, O. M. Exceptional Chemical and Thermal Stability of Zeolitic Imidazolate Frameworks. PNAS 2006, 103 (27), 10186-10191. https://doi.org/10.1073/pnas.0602439103.

(68) Rosi, N. L.; Kim, J.; Eddaoudi, M.; Chen, B.; O’Keeffe, M.; Yaghi, O. M. Rod Packings and Metal-Organic Frameworks Constructed from Rod-Shaped Secondary Building Units. J. Am. Chem. Soc. 2005, 127 (5), 1504-1518. https://doi.org/10.1021/JA0451230.

(69) Garzón-Tovar, L.; Carné-Sánchez, A.; Carbonell, C.; Imaz, I.; Maspoch, D. Optimised Room Temperature, Water-Based Synthesis of CPO-27-M Metal-Organic Frameworks with High SpaceTime Yields. J. Mater. Chem. A 2015, 3 (41), 20819-20826. https://doi.org/10.1039/C5TA04923G.

(70) Mason, J. A.; Sumida, K.; Herm, Z. R.; Krishna, R.; Long, Jeffrey. R. Evaluating Metal-Organic Frameworks for Post-Combustion Carbon Dioxide Capture via Temperature Swing Adsorption. Energy Environ. Sci. 2011, 4 (8), 3030-3040. https://doi.org/10.1039/C1EE01720A.

(71) Jin, C. X.; Shang, H. B. Synthetic Methods, Properties and Controlling Roles of Synthetic Parameters of Zeolite Imidazole Framework-8: A Review. J. Solid State Chem. 2021, 297, 122040. https://doi.org/10.1016/J.JSSC.2021.122040.

(72) Guo, J.; MacMillan, B.; Zamiri, M. S.; Balcom, B. J. Magnetic Resonance T1-T2* and T1p-T2* Relaxation Correlation Measurements in Solid-like Materials with Non-Exponential Decays. J. Magn. Res. 2021, 328, 107005. https://doi.org/10.1016/j.jmr.2021.107005.

(73) Beldon, P. J.; Fábián, L.; Stein, R. S.; Thirumurugan, A.; Cheetham, A. K.; Friščić, T. Rapid RoomTemperature Synthesis of Zeolitic Imidazolate Frameworks by Using Mechanochemistry. Angew. Chem. Int. Ed. 2010, 49 (50), 9640-9643. https://doi.org/10.1002/ANIE.201005547.

(74) Friščić, T.; Childs, S. L.; Rizvi, S. A. A.; Jones, W. The Role of Solvent in Mechanochemical and Sonochemical Cocrystal Formation: A Solubility-Based Approach for Predicting Cocrystallisation Outcome. CrystEngComm 2009, 11 (3), 418-426. https://doi.org/10.1039/B815174A.

(75) Xiao, T.; Liu, D. The Most Advanced Synthesis and a Wide Range of Applications of MOF-74 and Its Derivatives. Micropor. Mesopor. Mat. 2019, 283, 88-103.

https://doi.org/10.1016/j.micromeso.2019.03.002. 
(76) Tanaka, S.; Nagaoka, T.; Yasuyoshi, A.; Hasegawa, Y.; Denayer, J. F. M. Hierarchical Pore Development of ZIF-8 MOF by Simple Salt-Assisted Mechanosynthesis. Cryst. Growth Des. 2018, 18 (1), 274-279. https://doi.org/10.1021/acs.cgd.7b01211.

(77) BP, H.; DE, C.; L, G.; P, H.; SL, J. Feedback Kinetics in Mechanochemistry: The Importance of Cohesive States. Angew. Chem. Int. Ed. 2017, 56 (48), 15252-15256. https://doi.org/10.1002/ANIE.201706723.

(78) Rô Me Canivet, J.; Fateeva, A.; Guo, Y.; Coasne, B.; Farrusseng, D. Water Adsorption in MOFs: Fundamentals and Applications. Chem. Soc. Rev 2014, 43 (16), 5594-5617. https://doi.org/10.1039/c4cs00078a.

(79) Lowe, I. J.; Norberg, R. E. Free-Induction Decays in Solids. Phys. Rev. 1957, 107, 46-61. https://doi.org/10.1103/PhysRev.107.46.

(80) Derbyshire, W.; van den Bosch, M.; van Dusschoten, D.; MacNaughtan, W.; Farhat, I. A.; Hemminga, M. A.; Mitchell, J. R. Fitting of the Beat Pattern Observed in NMR Free-Induction Decay Signals of Concentrated Carbohydrate-Water Solutions. J. Magn. Res. 2004, 168 (2), 278283. https://doi.org/10.1016/j.jmr.2004.03.013. 


\section{Relaxation Time Correlation NMR for Mechanochemical Reaction Monitoring of Metal-Organic Frameworks}

Madeleine E. Leger ${ }^{a b}$, Jiangfeng Guo ${ }^{b}$, Bryce MacMillan ${ }^{b}$, Hatem M. Titic, Tomislav Friščićc, Barry A. Blight ${ }^{*}$, and Bruce Balcom ${ }^{a, b^{*}}$.

${ }^{a}$ Department of Chemistry, University of New Brunswick, Fredericton, New Brunswick, E3B $5 \mathrm{~A} 3$, Canada

${ }^{b}$ UNB MRI Centre, Department of Physics, University of New Brunswick, Fredericton, New Brunswick, E3B 5A3, Canada

${ }^{c}$ Department of Chemistry, McGill University, Montreal, Quebec, H3A 0G4, Canada

* Corresponding author: bjb@unb.ca,b.blight@unb.ca

\section{Supplementary Material}

Table of Contents

\begin{tabular}{|l|l|}
\hline S1: Experimental & S2-S3 \\
\hline S2: Relaxation Time Values & S4-S5 \\
\hline S3: 1D Relaxation Time Plots & S6-13 \\
\hline S4: Non-Exponential Relaxation Time Correlation Plots & S14-S15 \\
\hline S5: PRXD Analysis & S16 \\
\hline S6: SEM and EDS Analysis & S17-S20 \\
\hline S7: TGA Analysis & S21 \\
\hline S8: References & S22 \\
\hline
\end{tabular}




\section{S1: Methods}

\section{$\underline{\text { Probe and Teflon vials }}$}

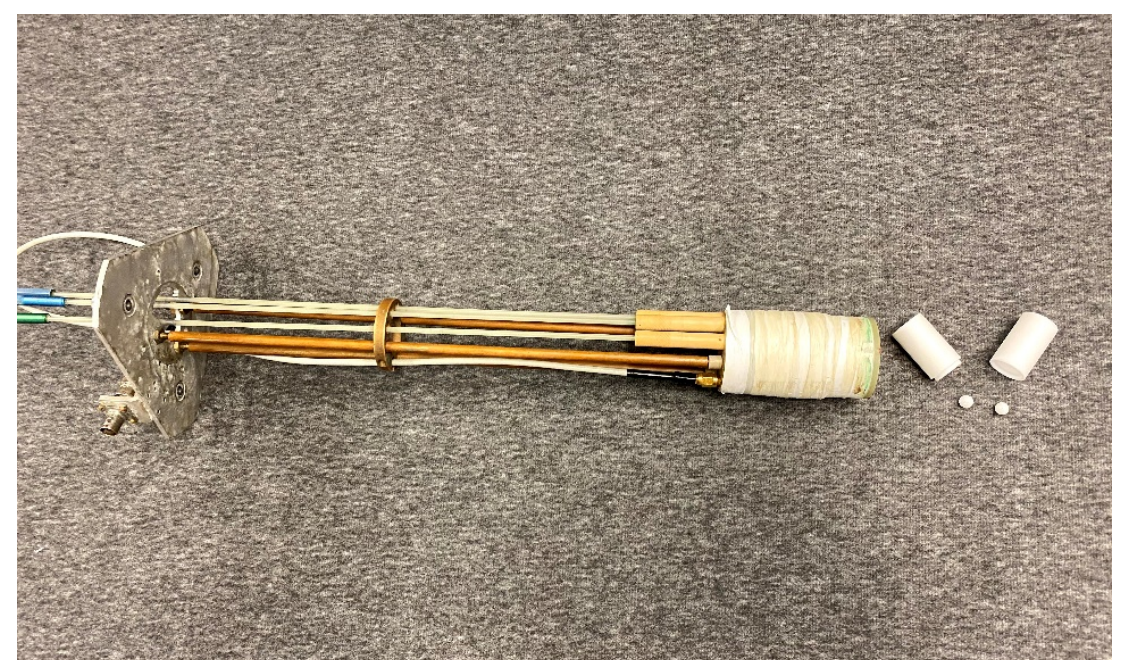

Figure S1. Doty DS1-874 ${ }^{1} \mathrm{H}$ RF probe, small $7.5 \mathrm{~mL}$ Teflon jar, and two small $7 \mathrm{~mm}$ zirconia balls.

\section{$\underline{\text { PXRD }}$}

The identities of the all reactants were confirmed through X-ray powder patterns that were collected on a Bruker D8 Advance spectrometer in the UNB geochemical and spectrographic facilities. Fine powder samples (gently crushed in mortar when necessary) were packed into the circular well on the sample-holder, after which it was placed on the sample stage and scanned. The diffractometer was equipped with a two circle (theta-theta) goniometer housed in a radiation safety enclosure. The $\mathrm{X}$-ray source was a sealed, $2.2 \mathrm{~kW} \mathrm{Cu}$ X-ray tube, maintained at an operating current of $40 \mathrm{kV}$ and $25 \mathrm{~mA}$. The X-ray optics was that of standard BraggBrentano para-focusing mode with the X-rays diverging from a divergence slit $(1.00 \mathrm{~mm})$ at the tube to strike the sample and then converging through an anti-scatter receiving slit (1.00 $\mathrm{mm})$ and a detector slit $(0.20 \mathrm{~mm})$. The goniometer was computer controlled with independent stepper motors and optical encoders for the $\theta$ and $2 \theta$ circles with the smallest angular step size of $0.0001^{\circ} 2 \theta$. Samples were scanned in the range of $5-70^{\circ} 2 \theta$ A step size of $0.02^{\circ}$ and a step time of $1.0 \mathrm{sec}$ were used during the measurements. A peltier-cooled solid-state [Si(Li)] detector (Sol-X) with a useful energy range of 1 to $60 \mathrm{KeV}$ was used as the detector. No correction was made for $\mathrm{K}_{\beta}$ radiation. A set of $2^{\circ}$ Soller slits were used in order to lower horizontal beam divergence.

The identities of the after-milling products were obtained on a Bruker D2 PHASER diffractometer equipped with a LynxEye linear position sensitive detector (Bruker AXS, Madison, WI, USA), using Ni-filtered $\mathrm{CuK} \alpha$ radiation. The data were collected between $2 \theta$ 4$50^{\circ}$, at increment of $0.02^{\circ}$ and exposure time of $0.3 \mathrm{~s}$.

\section{$\underline{\text { SEM/EDS }}$}

SEM images and EDS data were collected on a JEOL JSM-6400 Scanning Electron Microscope equipped with an EDAX Genesis 4000 Energy Dispersive X-ray (EDS) analyser at the UNB Microscopy and Microanalysis Facility. EDS analysis was performed at an 
accelerating voltage of $15 \mathrm{kV}$ and a beam current of $1.5 \mathrm{nA}$, with a working distance of $14 \mathrm{~mm}$. Collection time was 50 seconds per analysis point.

\section{TGA}

TGA data were obtained on a TGA 5500 Discovery by TA Instruments. The samples were heated to $700^{\circ} \mathrm{C}$ at a rate of $10{ }^{\circ} \mathrm{C} / \mathrm{min}$ and a gas flow of $25 \mathrm{~mL} / \mathrm{min}$.

\section{MR measurement}

Solid materials have particularly interesting $T_{1}-T_{2} *$ behaviors. Solids commonly feature very long $T_{1}$ values and extremely short $T_{2}$ values. This is explained by Bloembergen-Purcell-Pound (BPP) theory which illustrates the theoretical relationship between $T_{1}$ and $T_{2}$ relaxation times and molecular mobility. ${ }^{1}$ BPP theory emphasizes the importance of correlation time and motion in determining MR lifetime. Solids have increasingly large T1 values as molecular and proton mobility decreases, and very short $\mathrm{T}_{2}$ values. Since $\mathrm{T}_{2} *$ decay is governed by $\mathrm{T}_{2}$, the $\mathrm{T}_{2} *$ decay of solids is very short. Indeed, in our study, a $\mathrm{T}_{1}$ of $47.7 \mathrm{~s}$ and a $\mathrm{T}_{2}{ }^{*}$ as short as $5.7 \mu \mathrm{s}$ were measured.

These unusual relaxation times heavily influenced our relaxation measurement and pulse sequence choices. Common relaxation time methodologies to obtain $\mathrm{T}_{1}-\mathrm{T}_{2}$ data based on multiple spin echoes are not appropriate for solid samples since the short-lived signal decays too rapidly compared to the echo time and long $90^{\circ}$ and $180^{\circ}$ pulses. A typical pulse sequence to obtain bulk $\mathrm{T}_{1}-\mathrm{T}_{2}{ }^{*}$ data employs inversion recovery, with FIDs acquired as a function of recovery time. This sequence is problematic since the minimum observation time of the sequence is too long to observe the short-lived $\mathrm{T}_{2} *$ signal.

To keep the measurements in this study straightforward, we utilized a saturation recovery pulse sequence to obtain $\mathrm{T}_{1}-\mathrm{T}_{2} *$ data. Saturation recovery (figure $4 \mathrm{~b}$ ) is the most appropriate MR sequence for solid-state analysis for a few reasons. First, it is a quick measurement. There is no need to wait five times the value of $\mathrm{T}_{1}$ or to use a full $90^{\circ}$ pulse during the sequence, which greatly reduces the minimum observation time of the sequence. Also, saturation recovery allows the measurement of very short $\mathrm{T}_{2} *$ decays because of the lack of multiple spin echoes or long RF pulses. To assure the acquisition of the short-lived FID decay, a short duration RF pulse, $5 \mu \mathrm{s}$, was utilized in this study. It is also important to have short acquisition deadtimes to have a chance at measuring the very short $\mathrm{T}_{2} *$ component. The deadtime (dt) was $4 \mu \mathrm{s}$.

a)

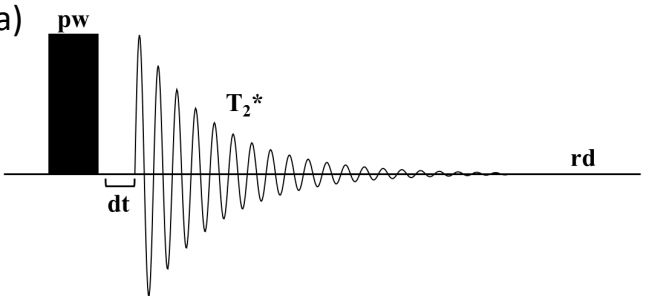

b)

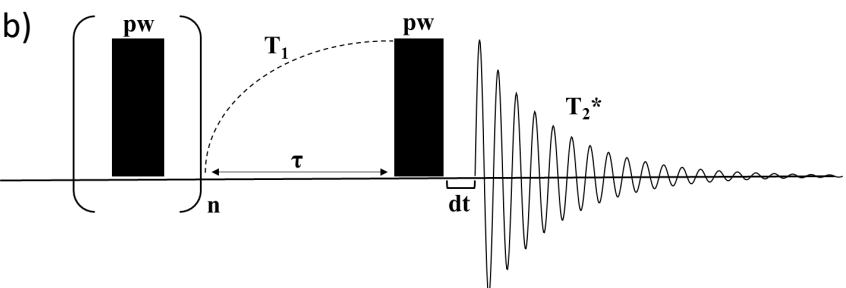

Figure S2. The pulse sequence of a (a) FID and (b) saturation recovery with some important parameters shown. The pulse wisth (pw) and probe dead time (dt) must be kept short to ensure capturing short-lived signal from the solid samples. In the FID sequence, the recycle delay (rd) is an important factor in measurement time since its value should be equal to five times the value of the longest $T_{1}$ in the sample. In the saturation recovery sequence, a series (n) of pw pulses are applied followed by a series of different lengths of recovery times $(\tau)$. The $\mathrm{T}_{2}{ }^{*}$ values are obtained from the FID curves, while the $T_{1}$ weighing depends on the longitudinal magnetization recovery after saturation. 
S2: Relaxation Time Values

\begin{tabular}{|c|c|c|c|c|}
\hline & Peak & 1 & 2 & 3 \\
\hline & $\begin{array}{l}\left(\mathrm{T}_{1}, \mathrm{~T}\right. \\
(\mathrm{s}, \mu \mathrm{s})\end{array}$ & & & \\
\hline Zinc oxide & & $(0.14,9.7)$ & $(0.96,12.1)$ & \\
\hline 2,5-dihydroxyterephthalic acid & & $(0.11,12.1)$ & $(47.7,12.1)$ & \\
\hline Before milling & & $(0.63,416)$ & & \\
\hline Milling 30 minutes & & $(0.10,432)$ & $(7.29,4.09)$ & \\
\hline After milling & & $(0.012,106)$ & $(0.20,6.8)$ & $(11.2,7.6)$ \\
\hline Zinc oxide & & $(0.14,9.7)$ & $(0.96,12.1)$ & \\
\hline 2-methylimidazole & & $(0.17,9.1)$ & $(24.9,9.1)$ & \\
\hline Before milling & & $(2.30,432)$ & $(0.15,10.5)$ & $(30.9,10.5)$ \\
\hline After milling & & $(0.78,210)$ & $(0.83,10.5)$ & $(28.8,10.5)$ \\
\hline After milling rinsed & & $(1.04,598)$ & $(0.08,10.1)$ & $(1.04,10.5)$ \\
\hline
\end{tabular}

Table S1. Relaxation times of ZIF-8 and MOF-74 synthesis. (corresponding numbered plots below)
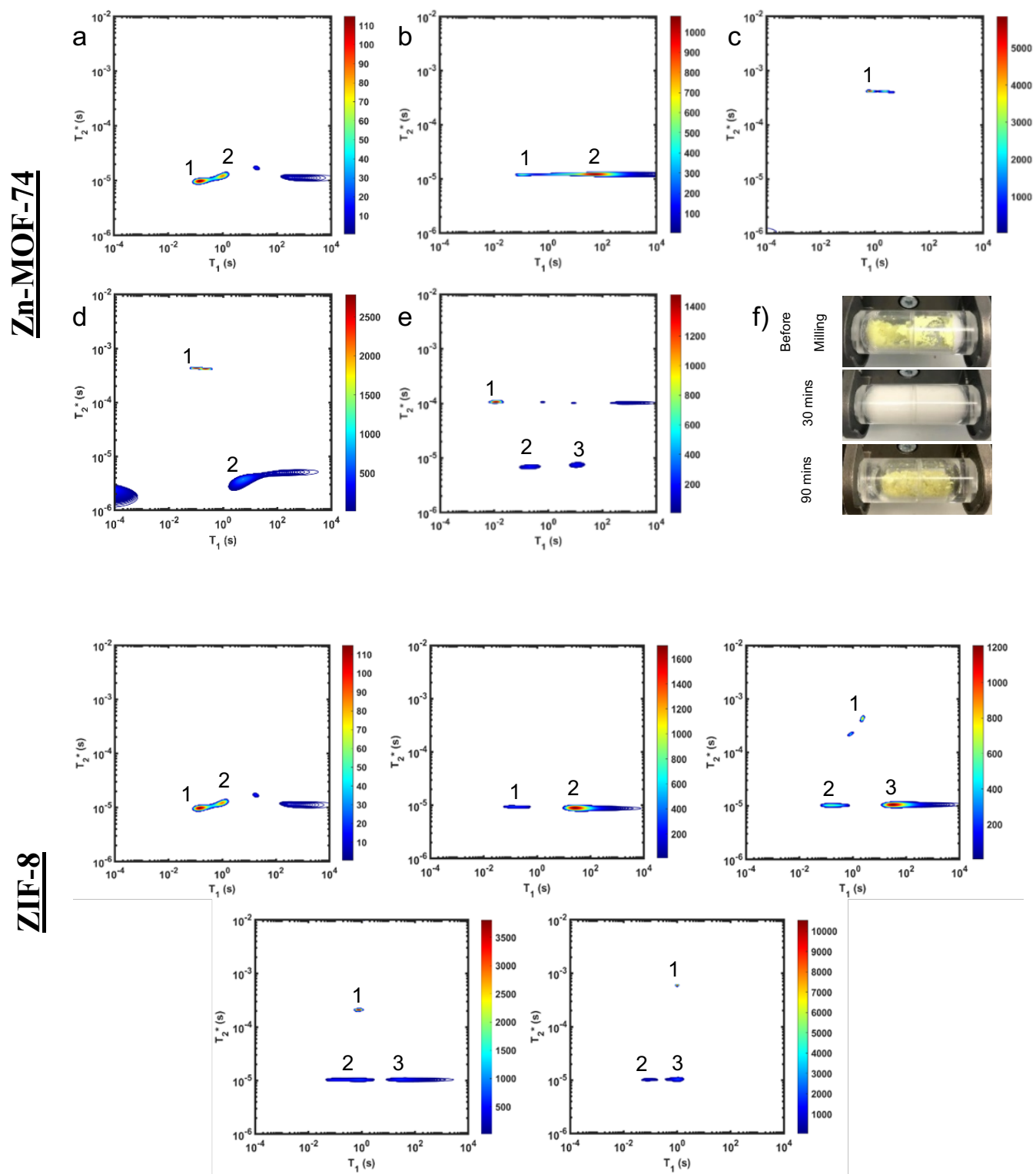


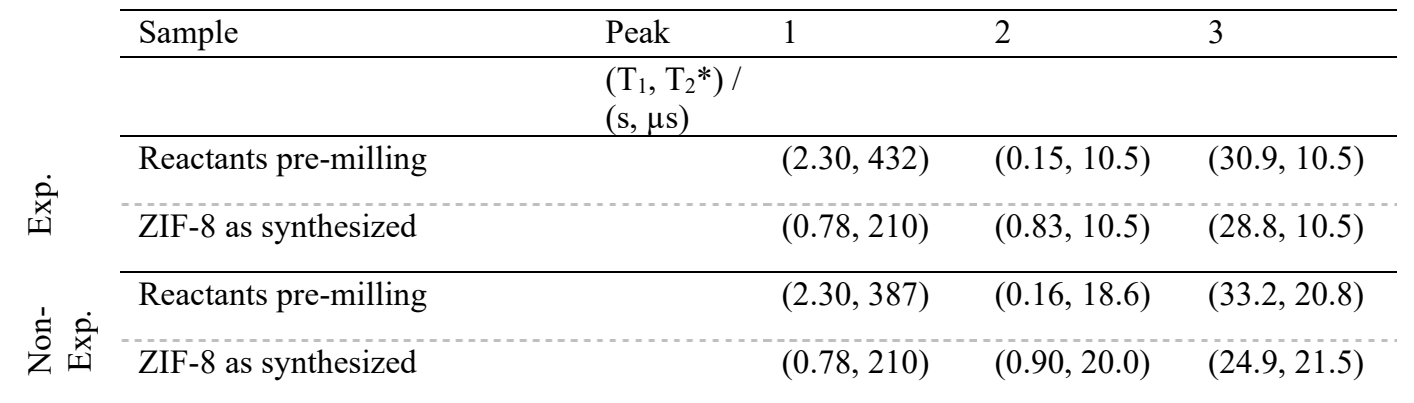

Table S2. Relaxation times of ZIF-8 synthesis comparing exponential and non-exponential processing. (corresponding numbered plots below)
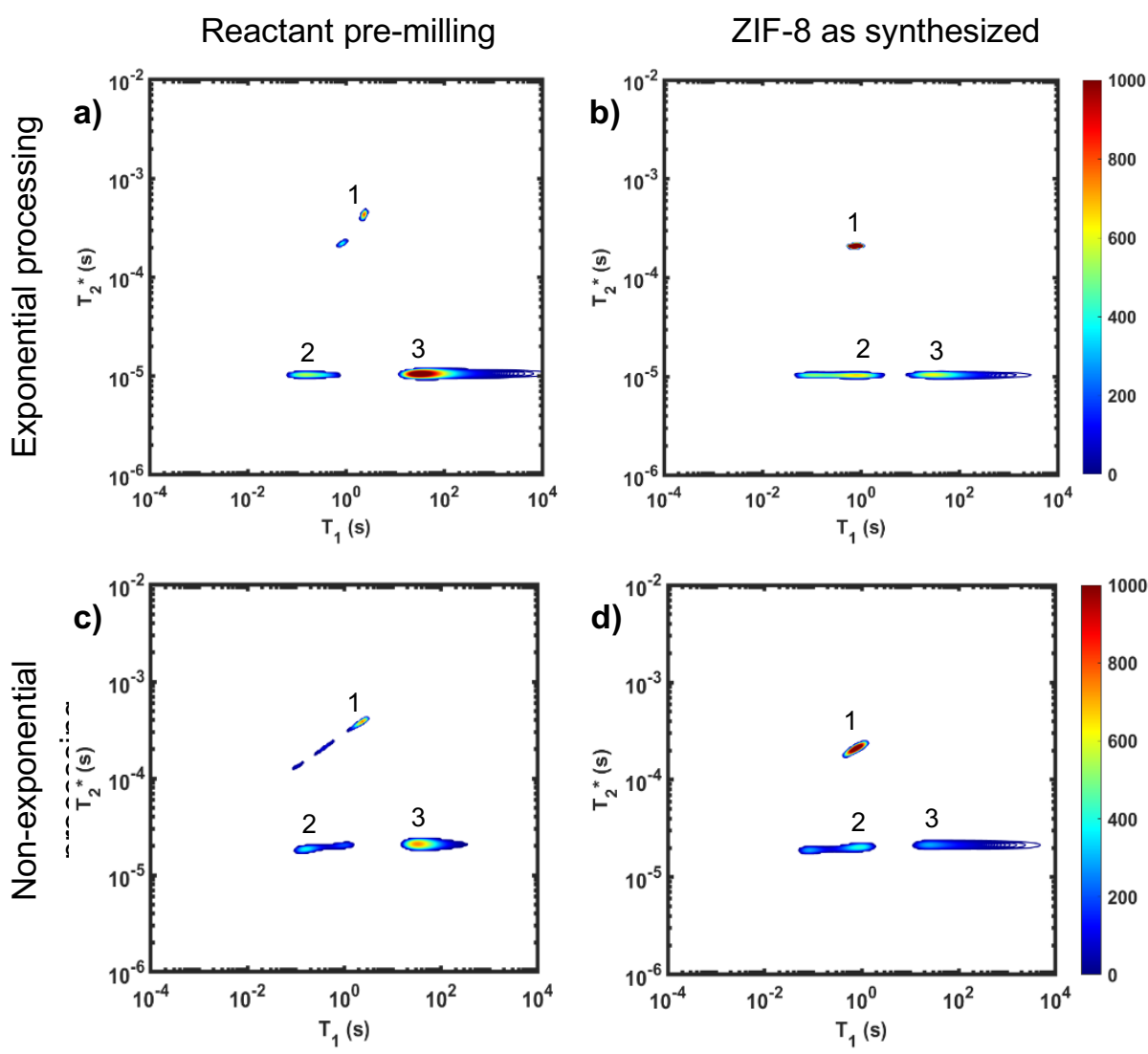
S3: 1D Relaxation Time Plots

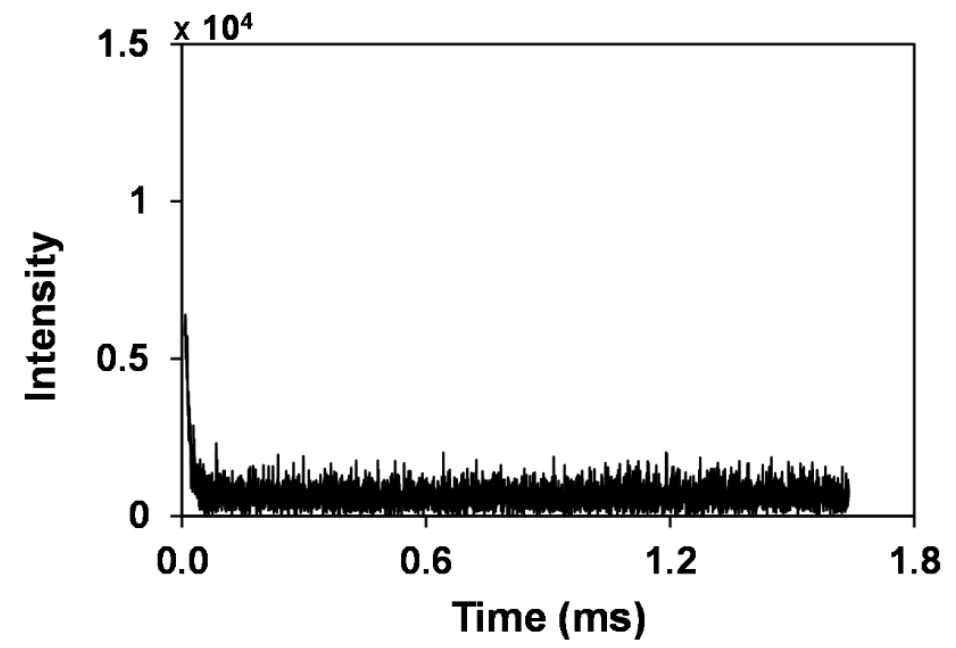

Figure S3. Free induction decay (FID) measurement of $\mathrm{T}_{2} *$ in zinc oxide sample.

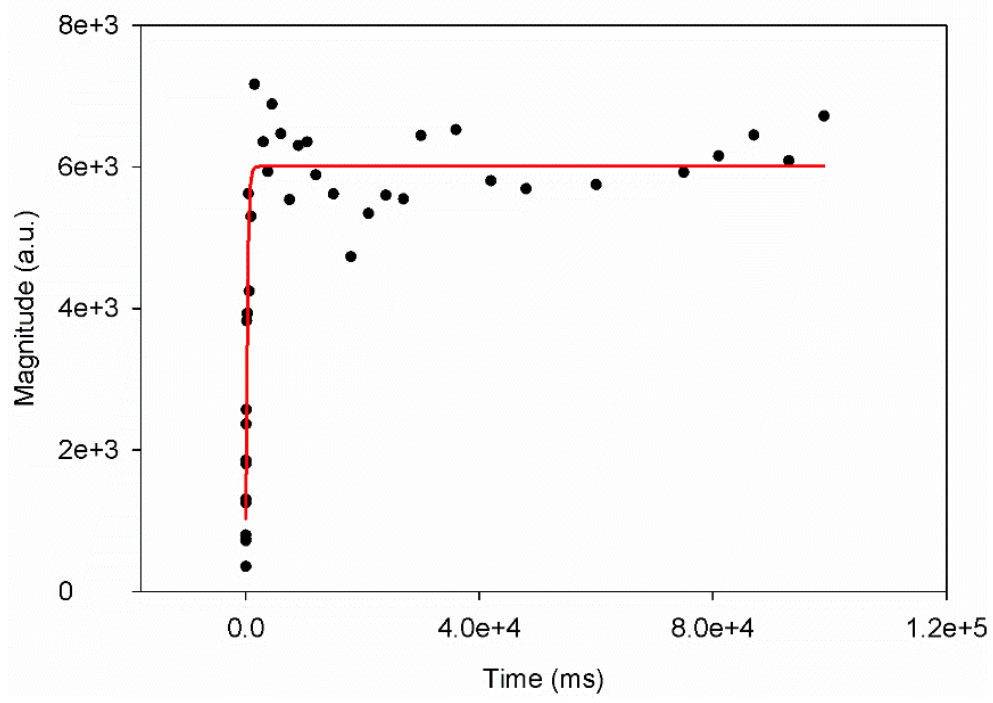

Figure S4. Saturation recovery measurement of $\mathrm{T}_{1}$ in zinc oxide sample. 


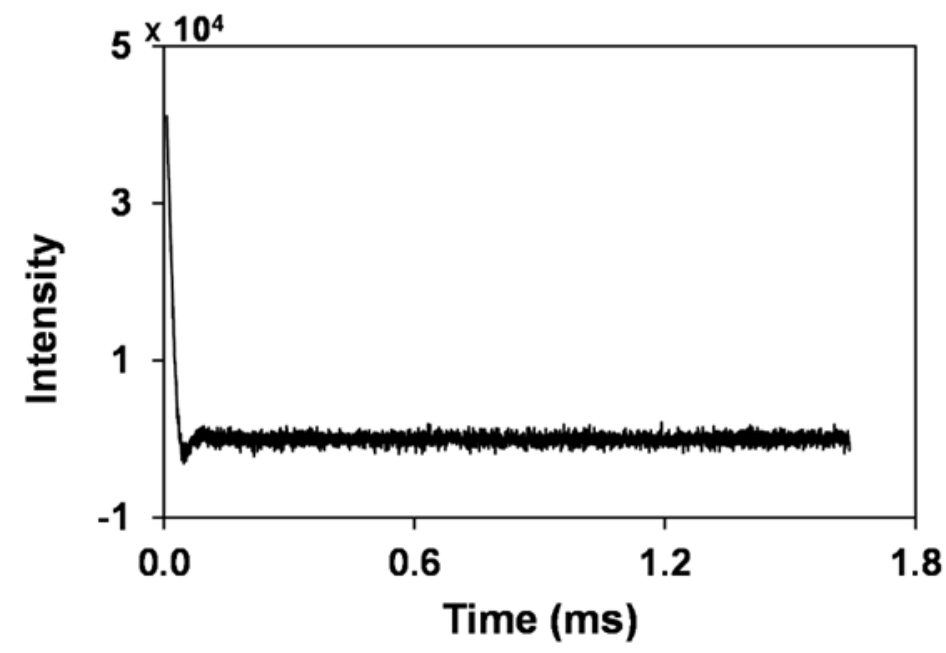

Figure S5. Free induction decay (FID) measurement of $\mathrm{T}_{2} *$ in 2,5-dihydroxyterephthalic acid sample.

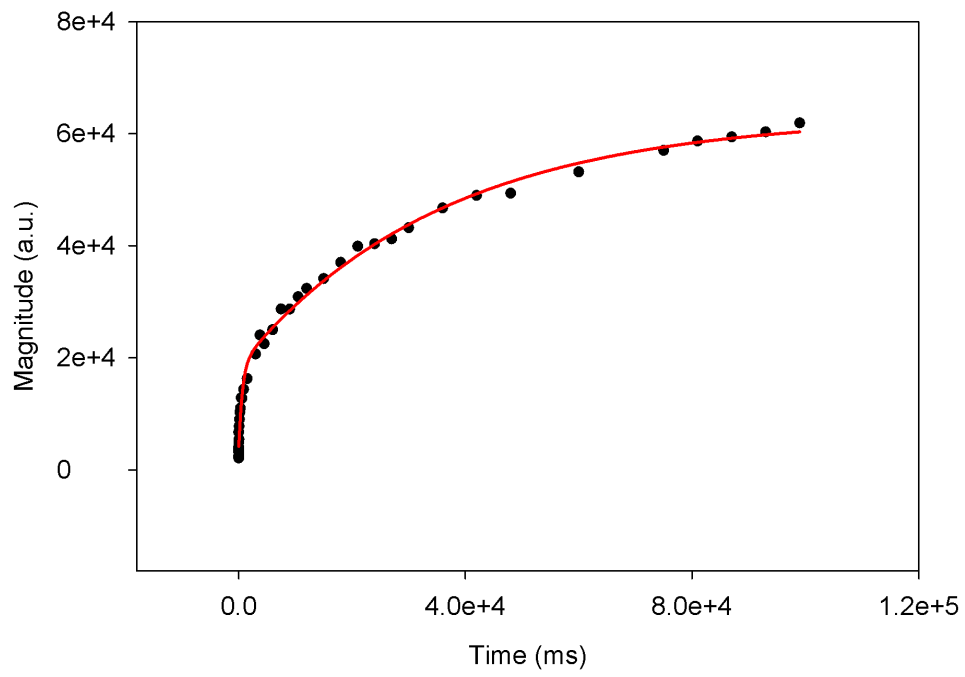

Figure S6. Saturation recovery measurement of $\mathrm{T}_{1}$ in 2,5-dihydroxyterephthalic acid sample. 


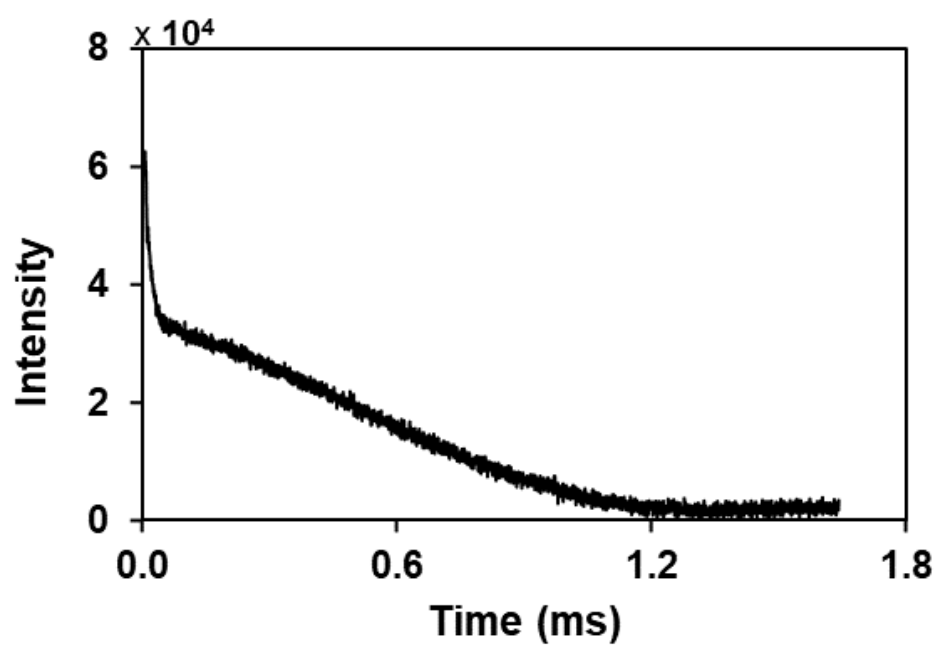

Figure S7. Free induction decay (FID) measurement of $\mathrm{T}_{2} *$ in $\mathrm{Zn}-\mathrm{MOF}-74$ mixture before milling sample.

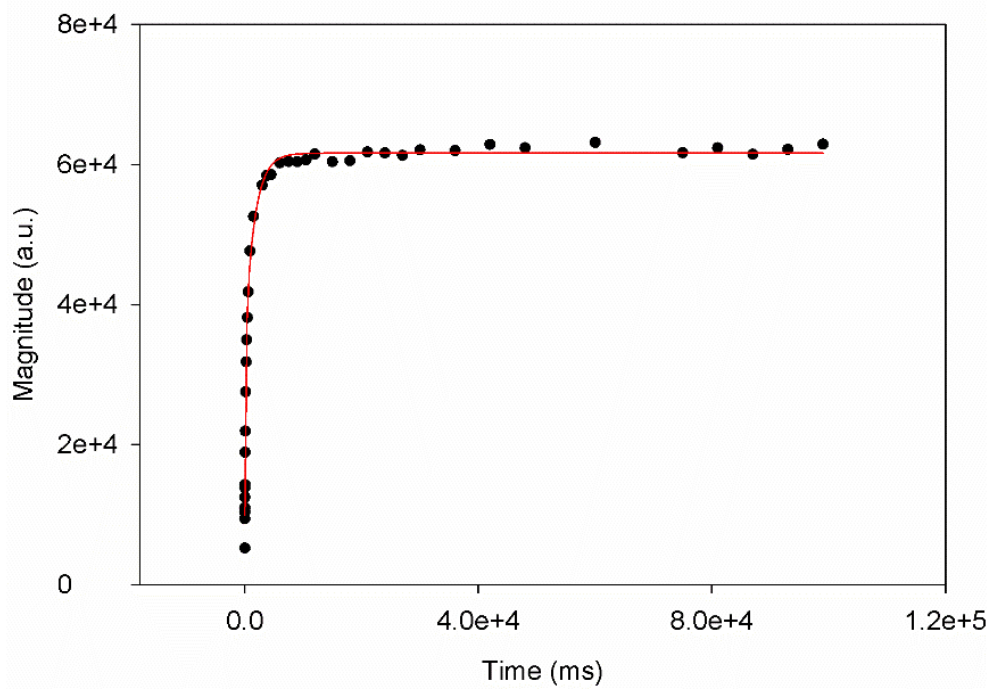

Figure S8. Saturation recovery measurement of $T_{1}$ in Zn-MOF-74 mixture before milling sample. 


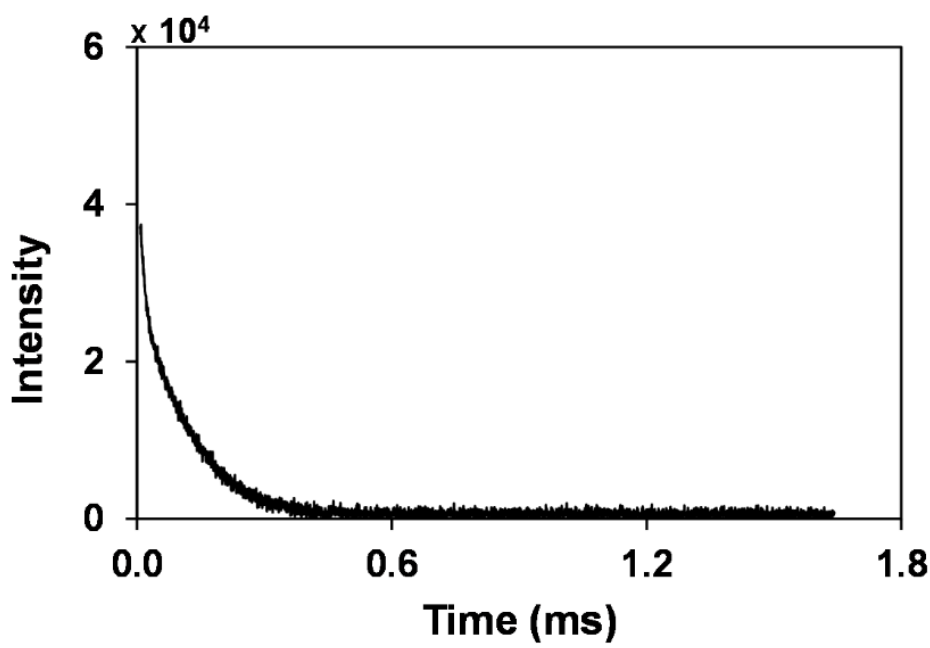

Figure S9. Free induction decay (FID) measurement of $\mathrm{T}_{2} *$ in $\mathrm{Zn}-\mathrm{MOF}-74$ as synthesized sample.

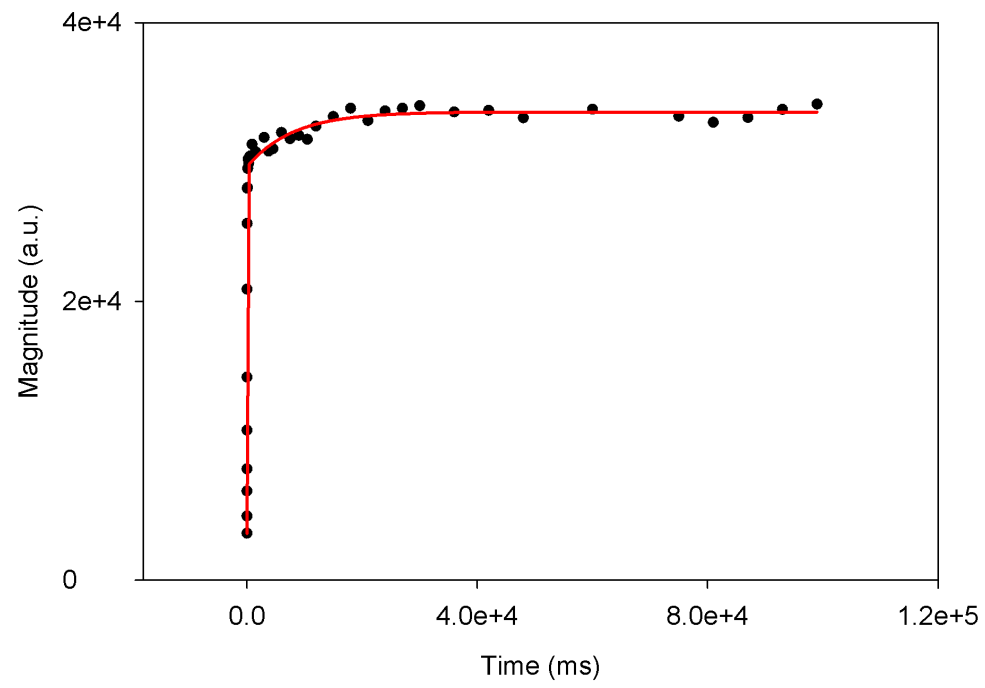

Figure S10. Saturation recovery measurement of $T_{1}$ in Zn-MOF-74 as synthesized sample. 


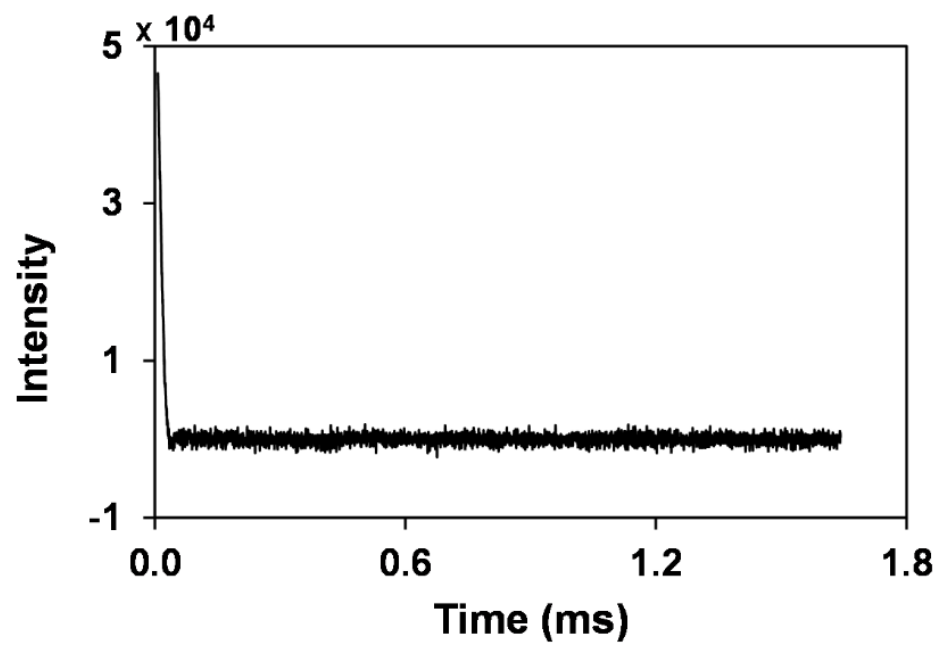

Figure S11. Free induction decay (FID) measurement of $\mathrm{T}_{2} *$ in 2-methylimidazole sample.

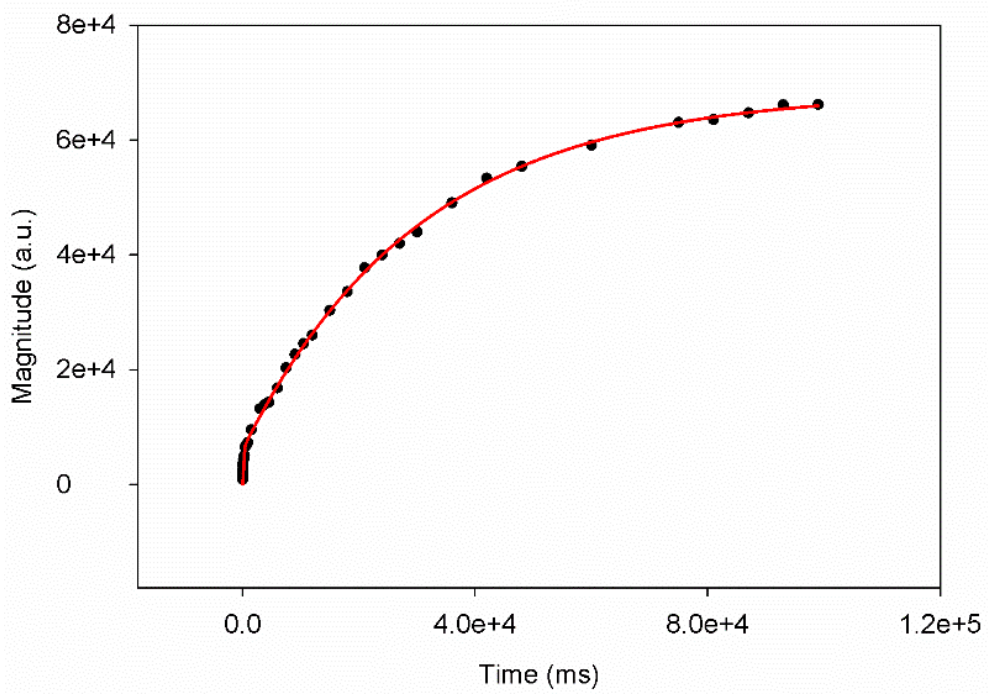

Figure S12. Saturation recovery measurement of $T_{1}$ in 2-methylimidazole sample. 


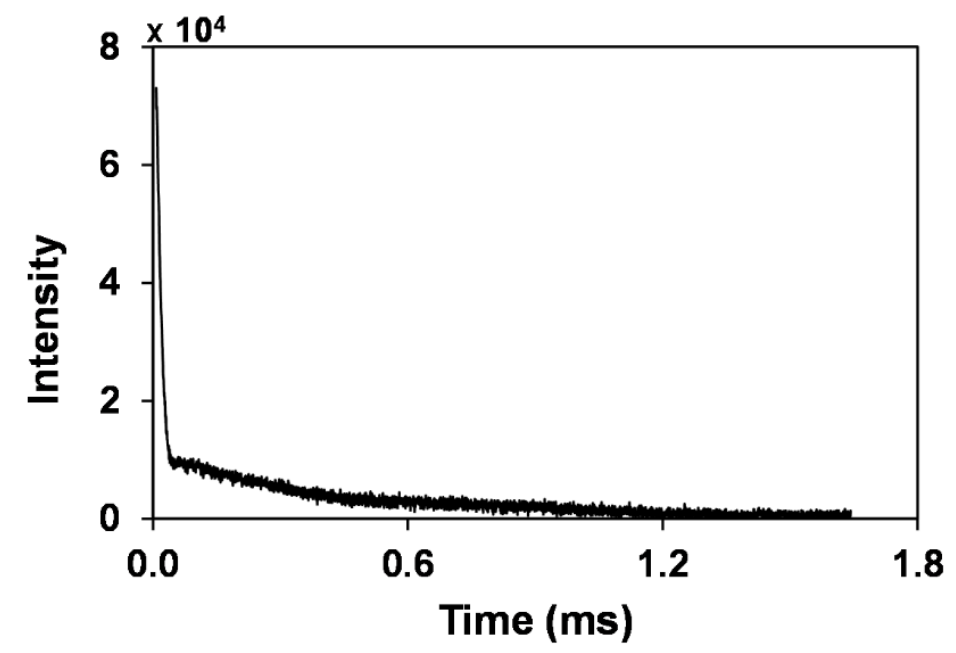

Figure S13. Free induction decay (FID) measurement of $\mathrm{T}_{2} *$ in ZIF-8 mixture before milling sample.

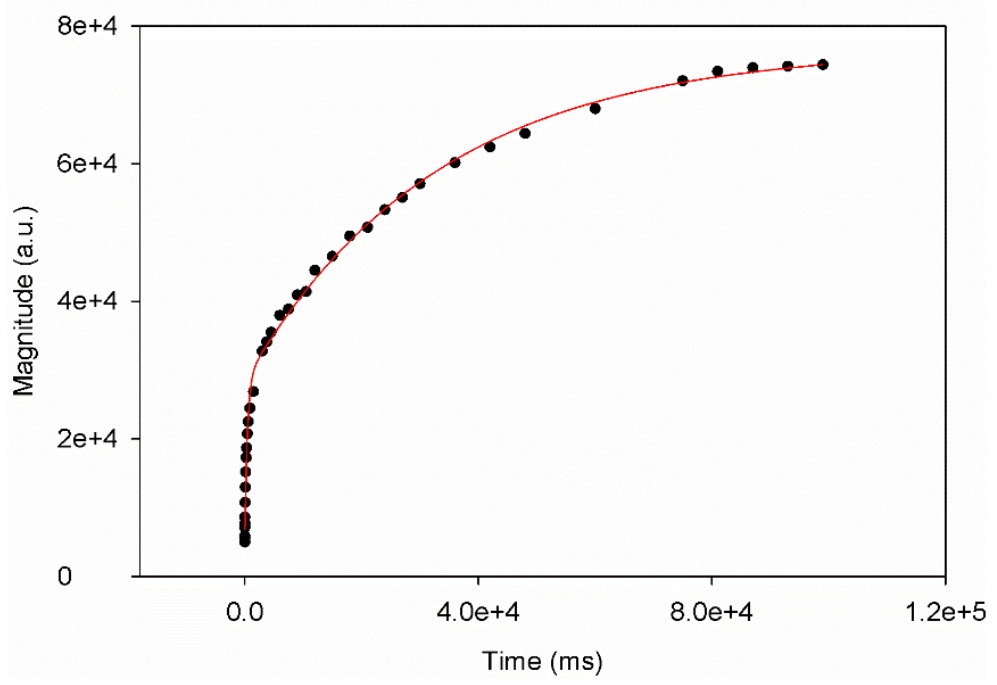

Figure S14. Saturation recovery measurement of $\mathrm{T}_{1}$ in ZIF-8 mixture before milling sample. 


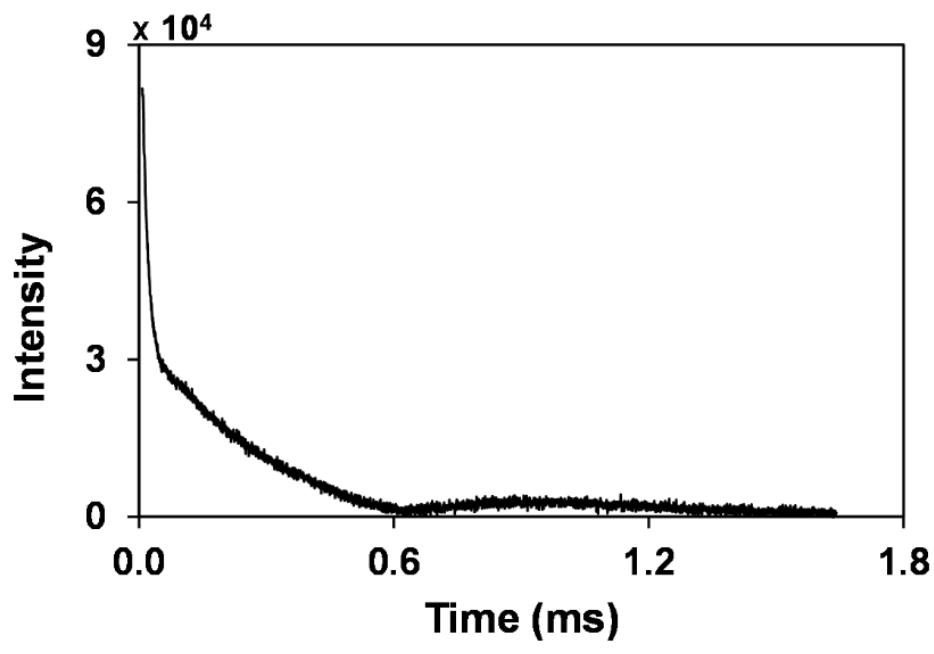

Figure S15. Free induction decay (FID) measurement of $\mathrm{T}_{2} *$ in ZIF-8 as synthesized sample.

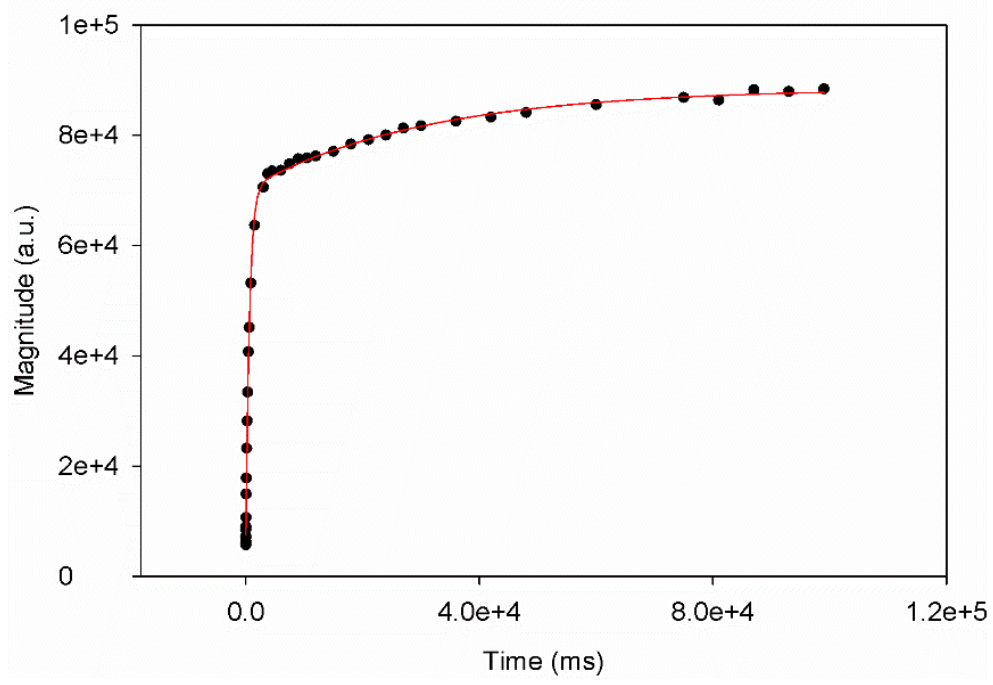

Figure S16. Saturation recovery measurement of $\mathrm{T}_{1}$ in $\mathrm{ZIF}-8$ as synthesized sample. 


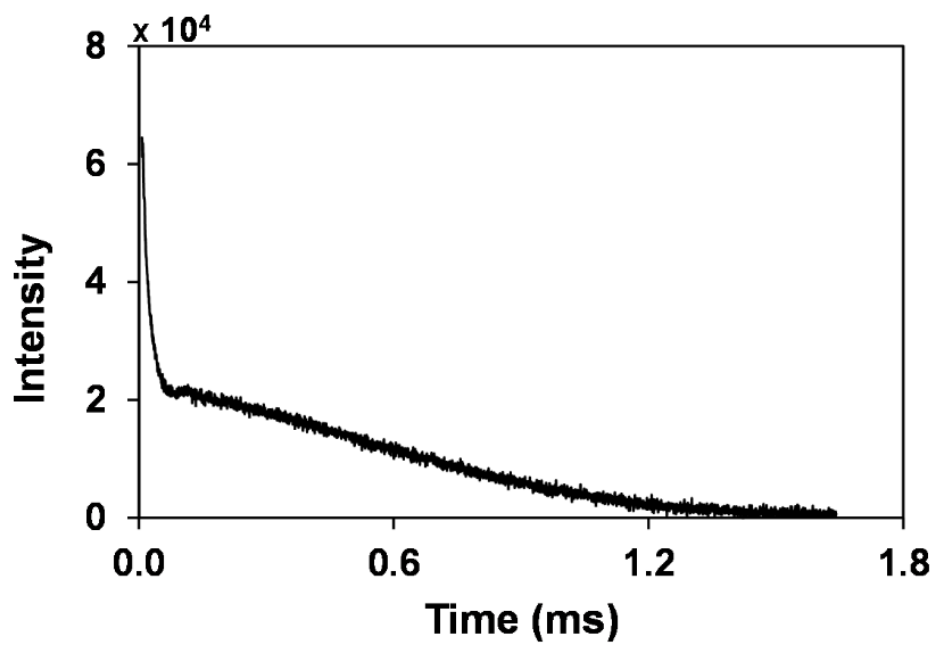

Figure S17. Free induction decay (FID) measurement of $\mathrm{T}_{2} *$ in ZIF-8 rinsed and dried sample.

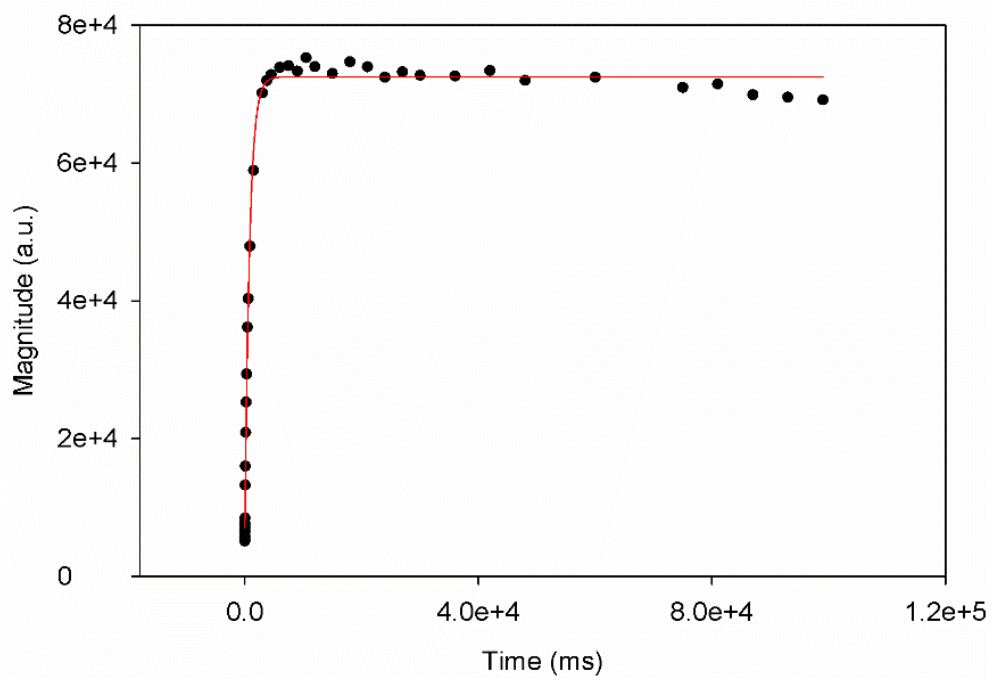

Figure S18. Saturation recovery measurement of $\mathrm{T}_{1}$ in $\mathrm{ZIF}-8$ rinsed and dried sample. 


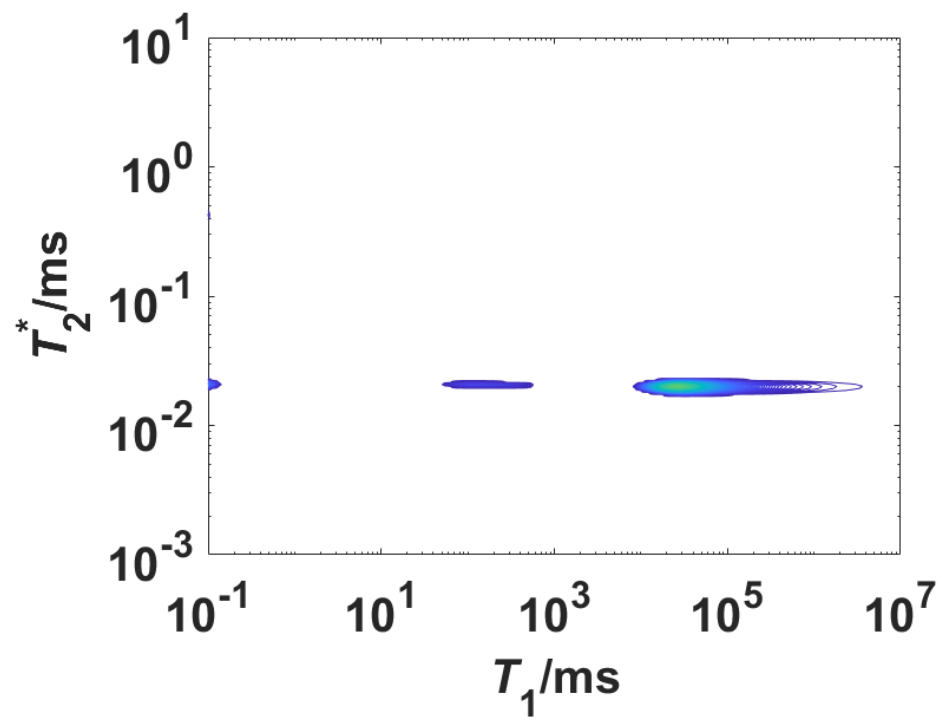

Figure S19. $\mathrm{T}_{1}-\mathrm{T}_{2} *$ correlation plot of 2-methylimidazole, using non-exponential processing.

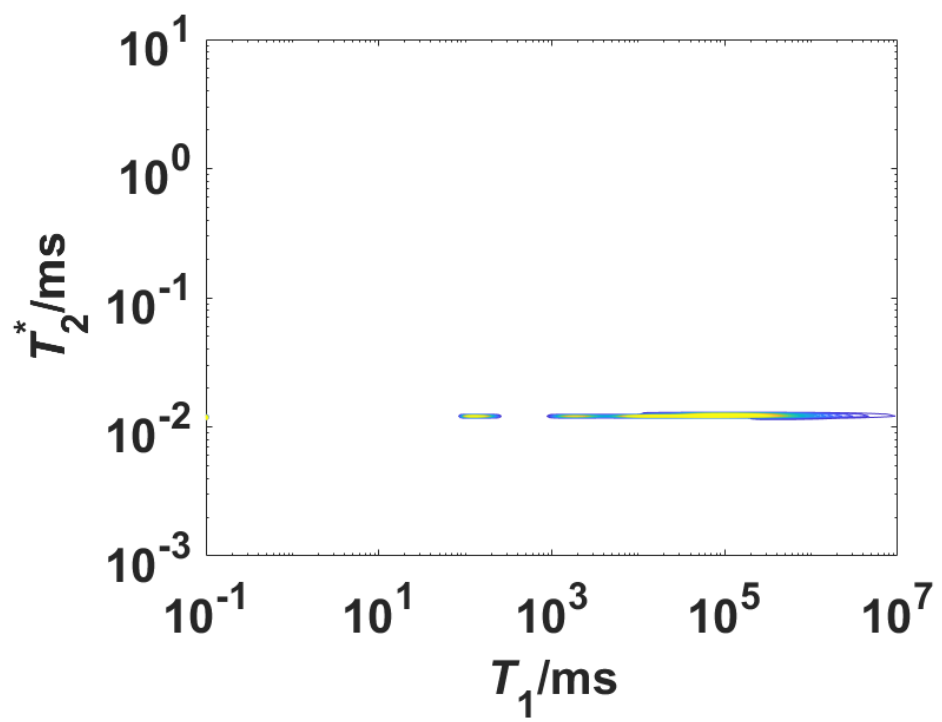

Figure S20. $\mathrm{T}_{1}-\mathrm{T}_{2} *$ correlation plot of 2,5-dihydroxyterephthalic acid, using non-exponential processing. 


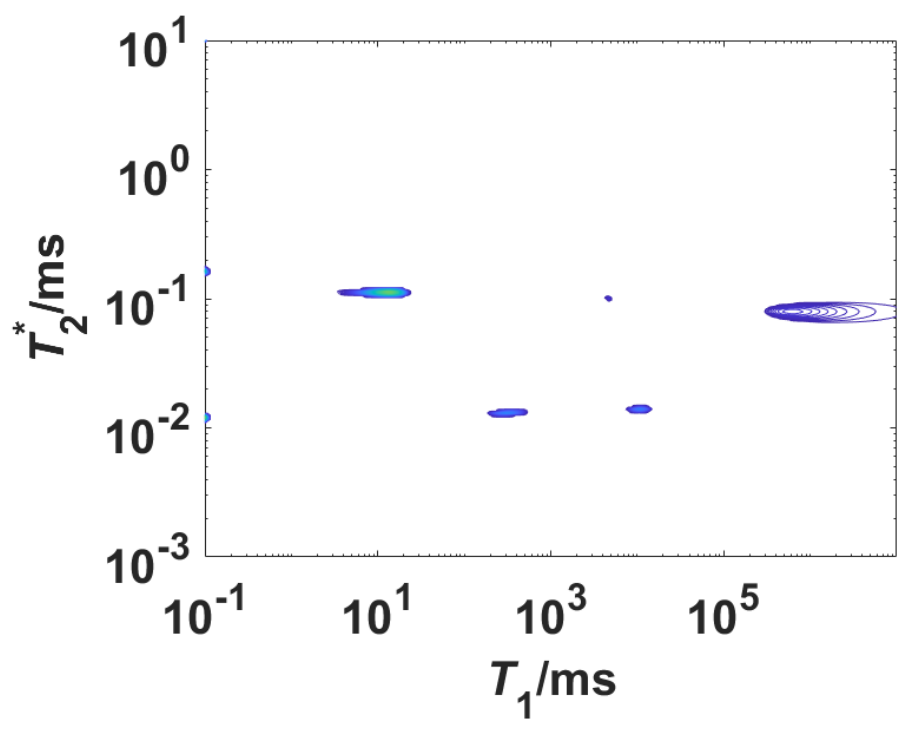

Figure S21. $\mathrm{T}_{1}-\mathrm{T}_{2} *$ correlation plot of $\mathrm{Zn}-\mathrm{MOF}-74$ after milling, using non-exponential processing. 


\section{S5: PXRD Analysis}

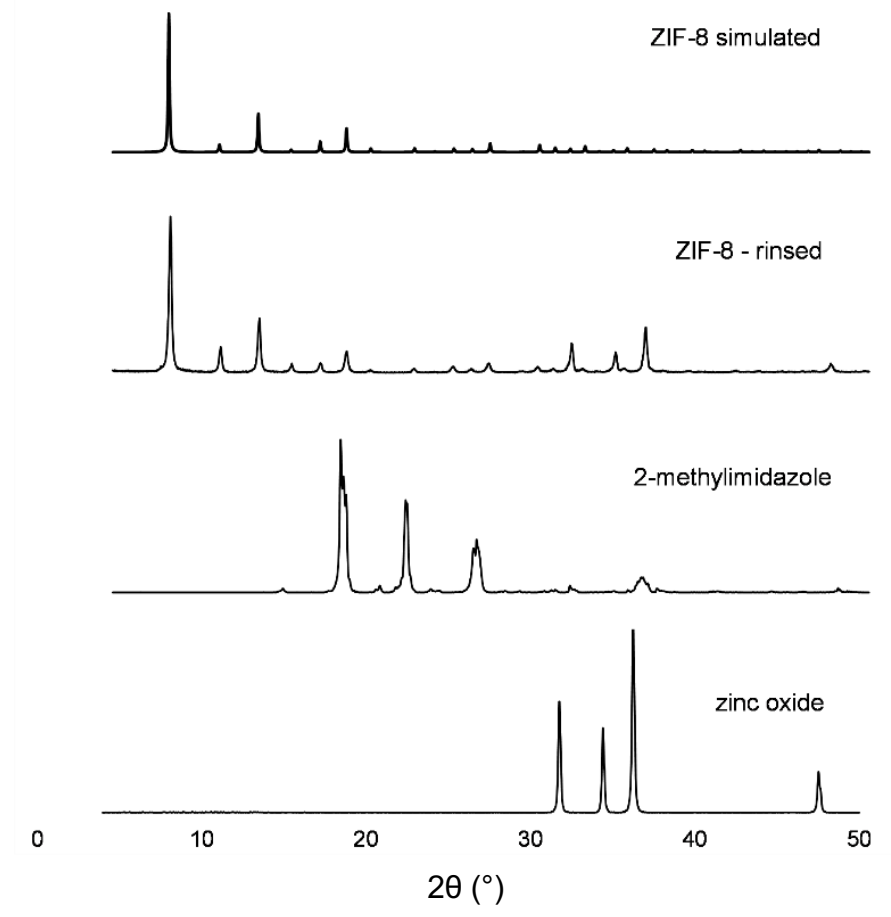

Figure S22. PXRD data of the ZIF-8 reaction. Simulated data obtained using Mercury. ${ }^{2}$

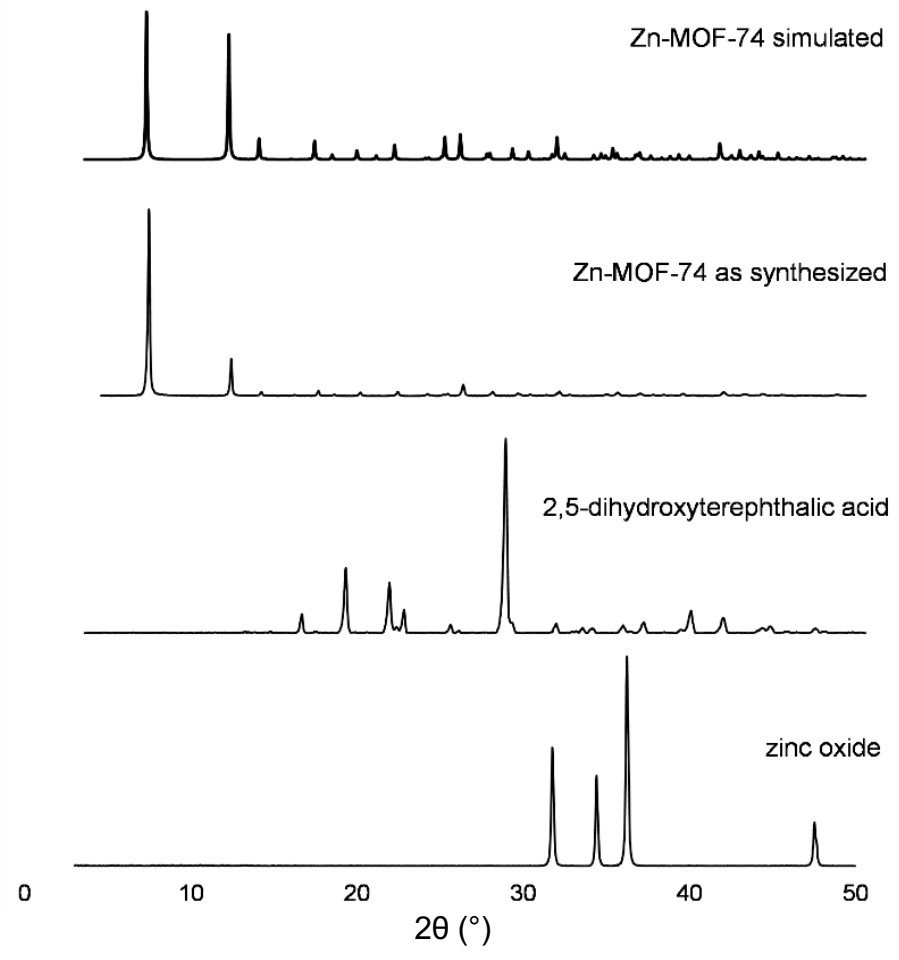

Figure S23. PXRD data of the Zn-MOF-74 reaction. Simulated data obtained using Mercury. ${ }^{2}$ 


\section{S6: SEM and EDS Analysis}

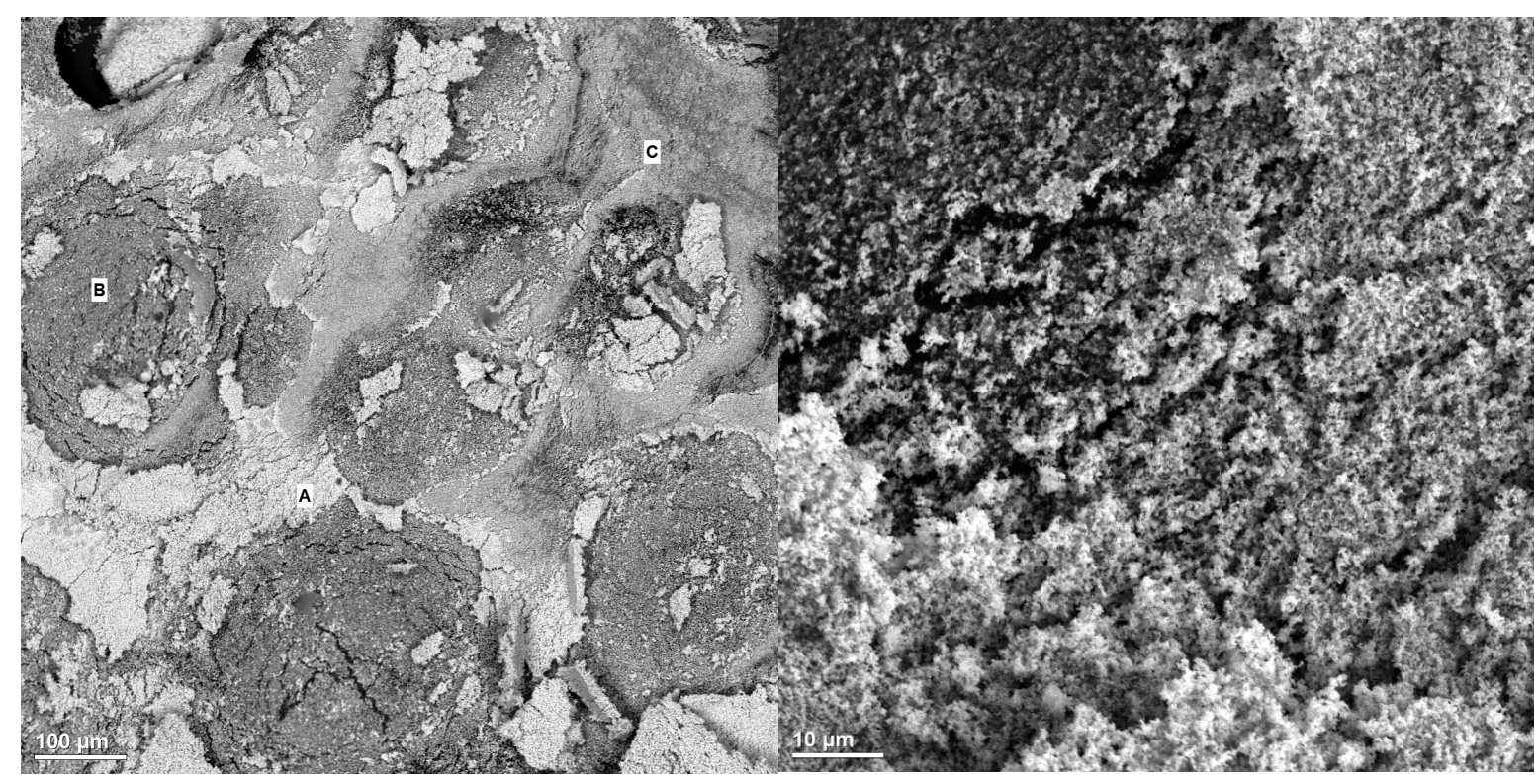

(a)

(b)

Figure S24. SEM micrographs of zinc oxide at $100 \mu \mathrm{m}$ (a) and $10 \mu \mathrm{m}$ (b).

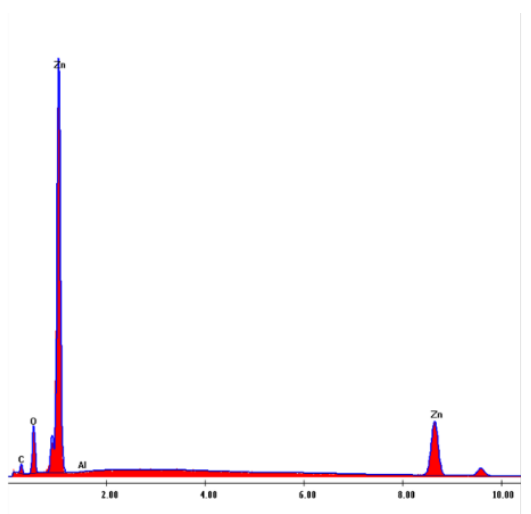

(a)

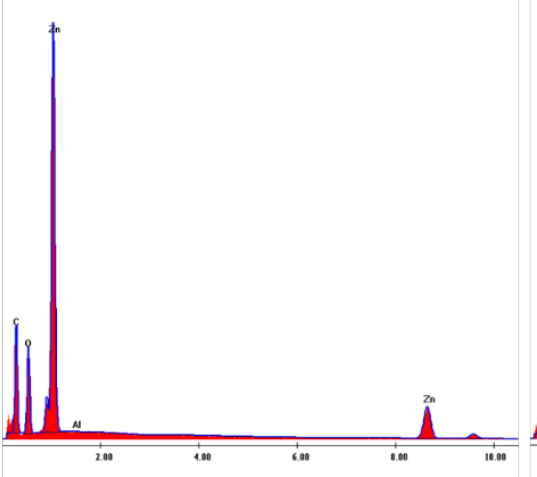

(b)

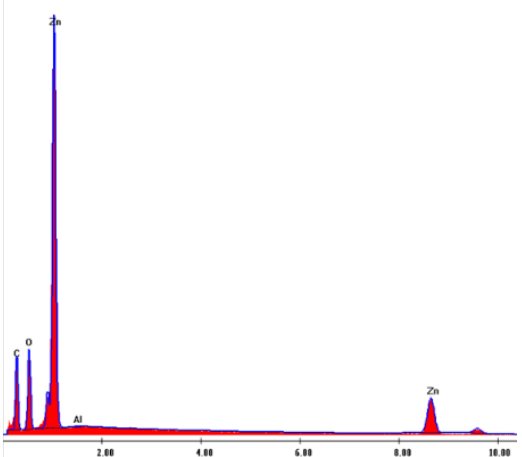

(c)

Figure S25. EDS analysis of zinc oxide (figure S24a, $100 \mu \mathrm{m}$ ). 


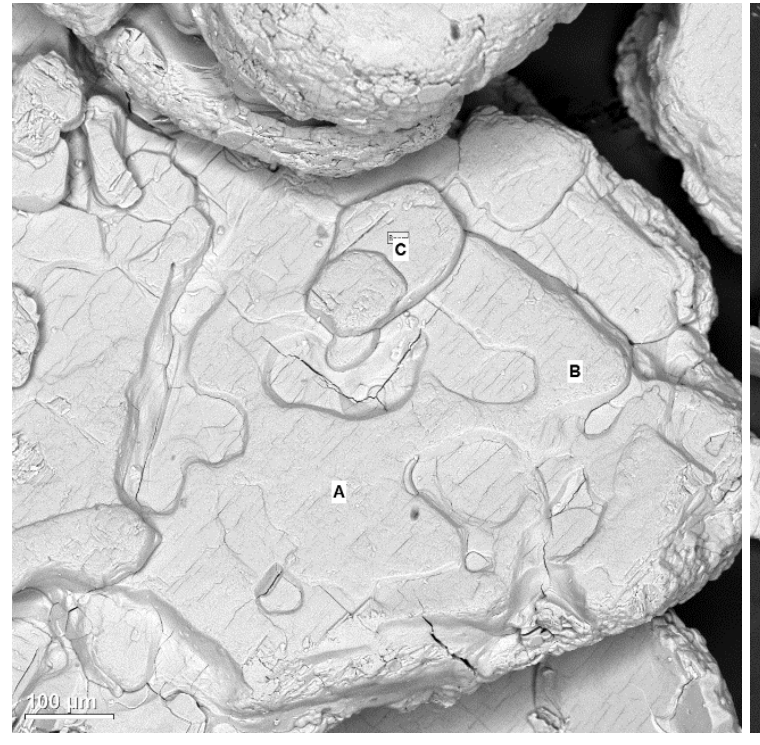

(a)

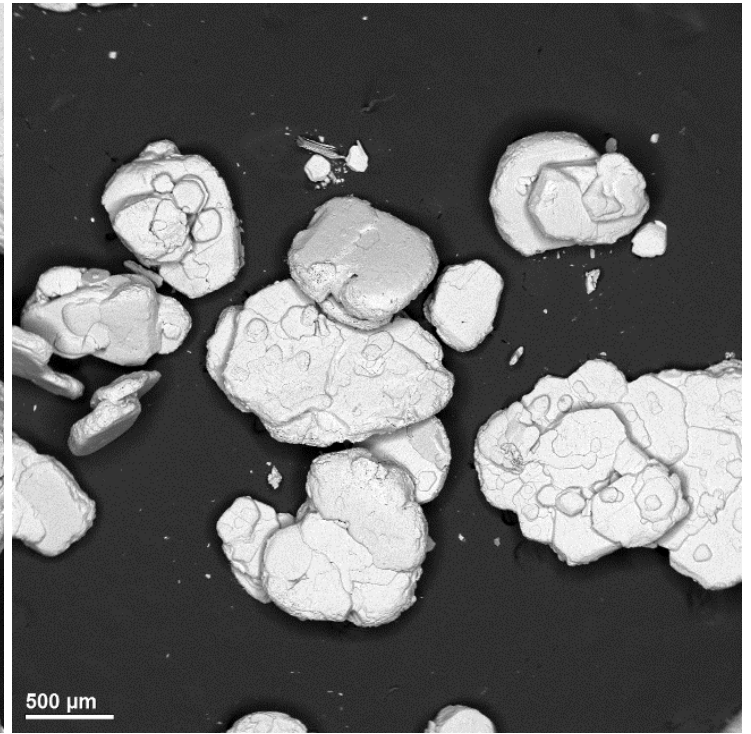

(b)

Figure S26. SEM micrographs of zinc acetate dihydrate at $100 \mu \mathrm{m}$ (a) and $500 \mu \mathrm{m}$ (b).

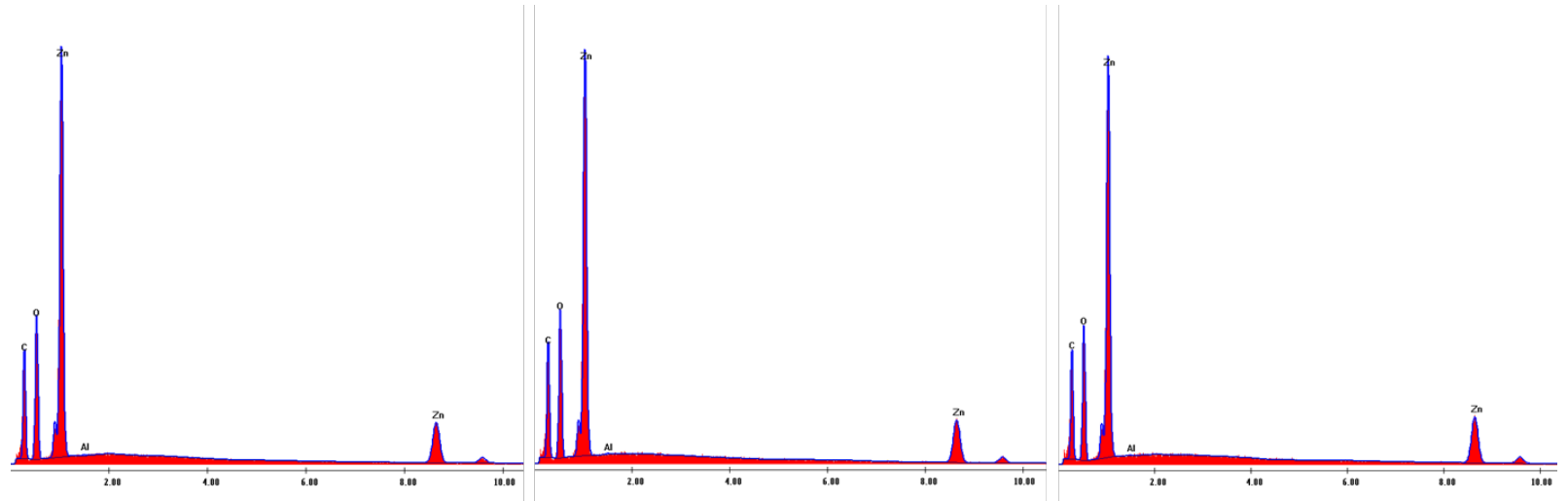

(a)

(b)

(c)

Figure S27. EDS analysis of zinc acetate dihydrate (figure S26a, $100 \mu \mathrm{m}$ ). 


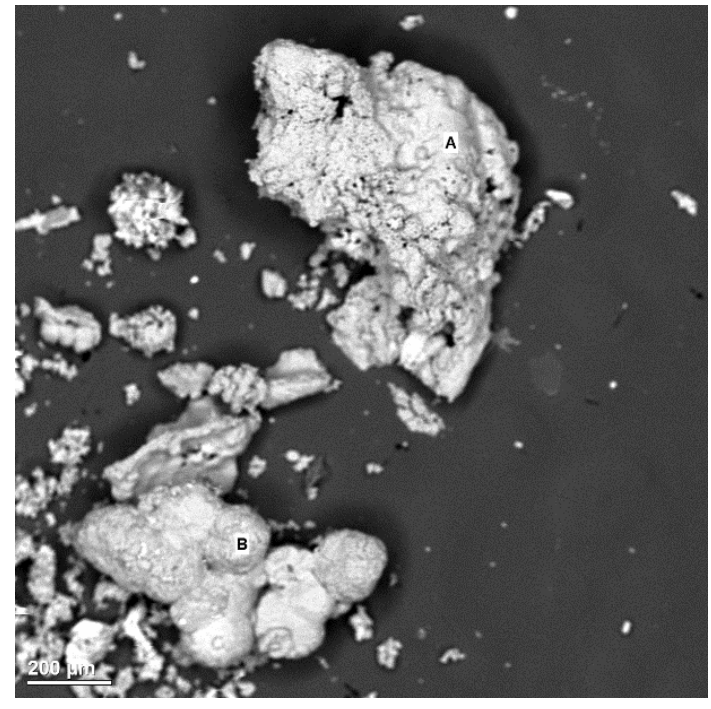

(a)

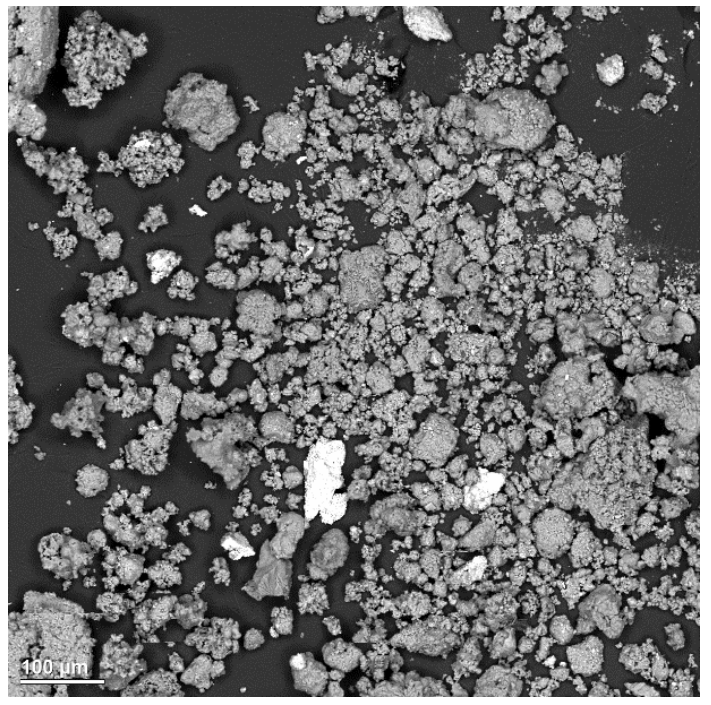

(b)

Figure S28. SEM micrographs of ZIF-8 after milling at $200 \mu \mathrm{m}$ (a) and $100 \mu \mathrm{m}$ (b).

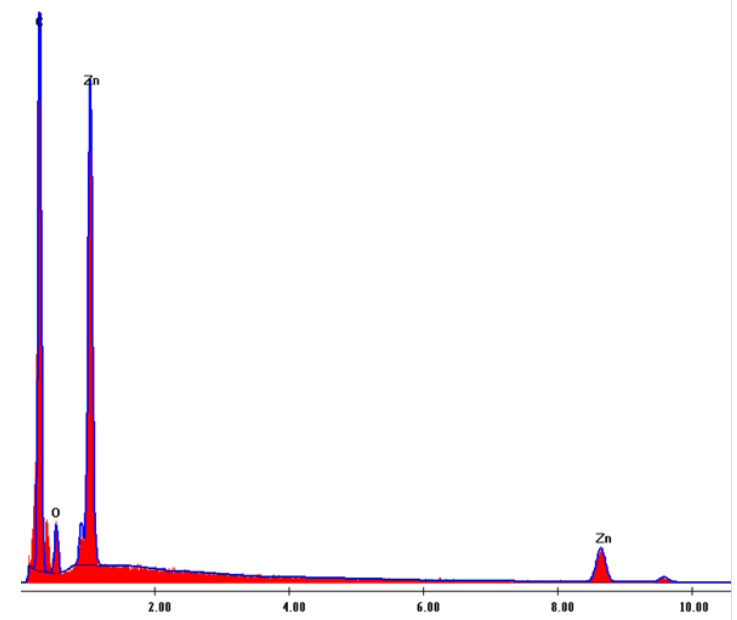

(a)

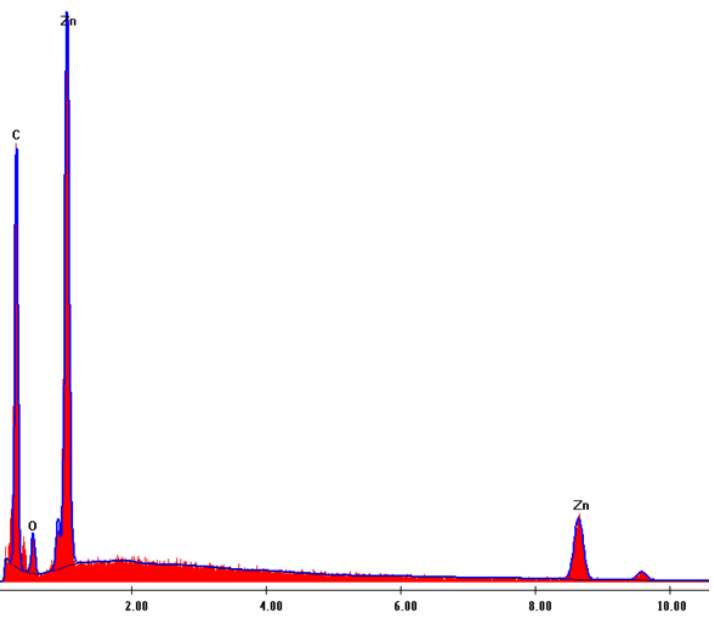

(b)

Figure S29. EDS analysis of ZIF-8 (figure S28a, $200 \mu \mathrm{m}$ ). 


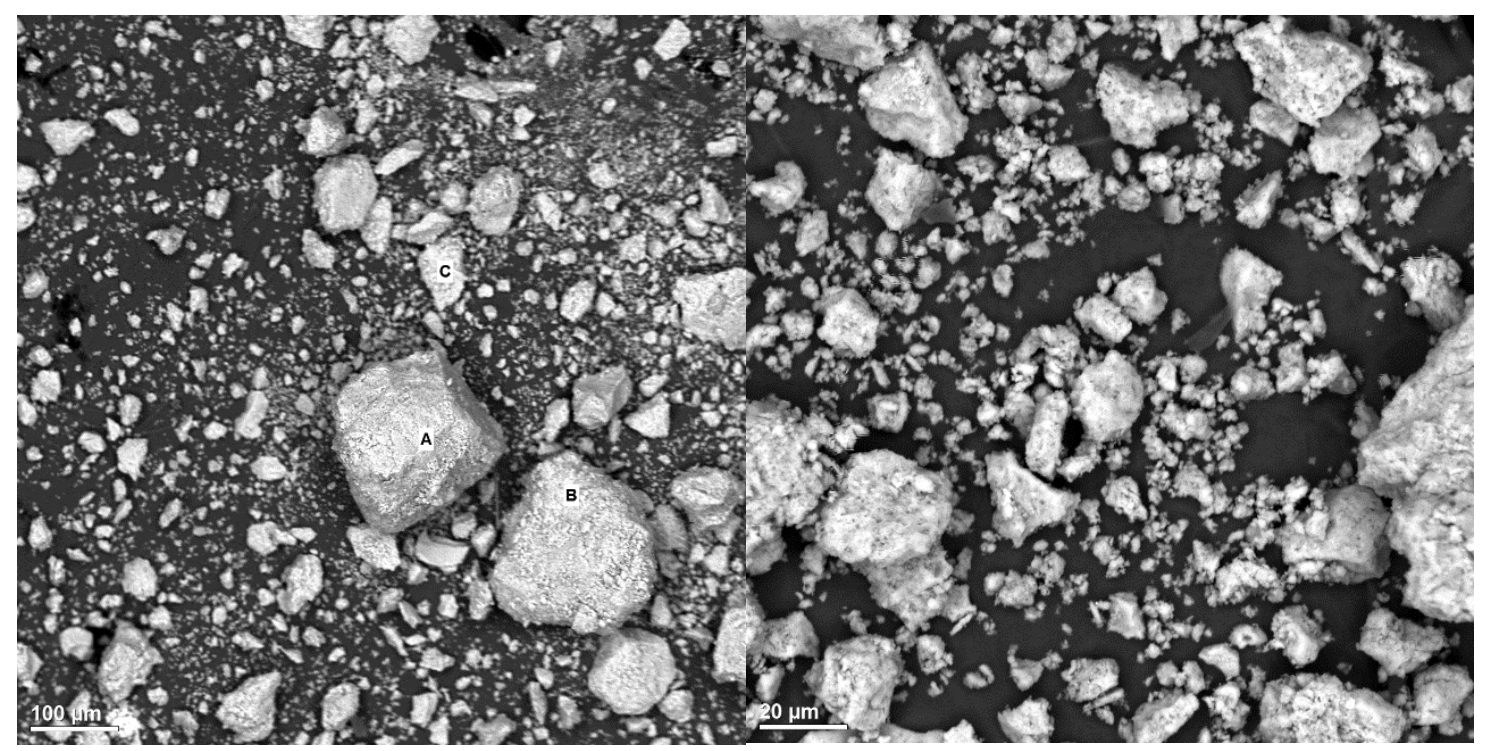

(a)

(b)

Figure S30. SEM micrographs of Zn-MOF-74 after milling at $100 \mu \mathrm{m}$ (a) and $20 \mu \mathrm{m}$ (b).

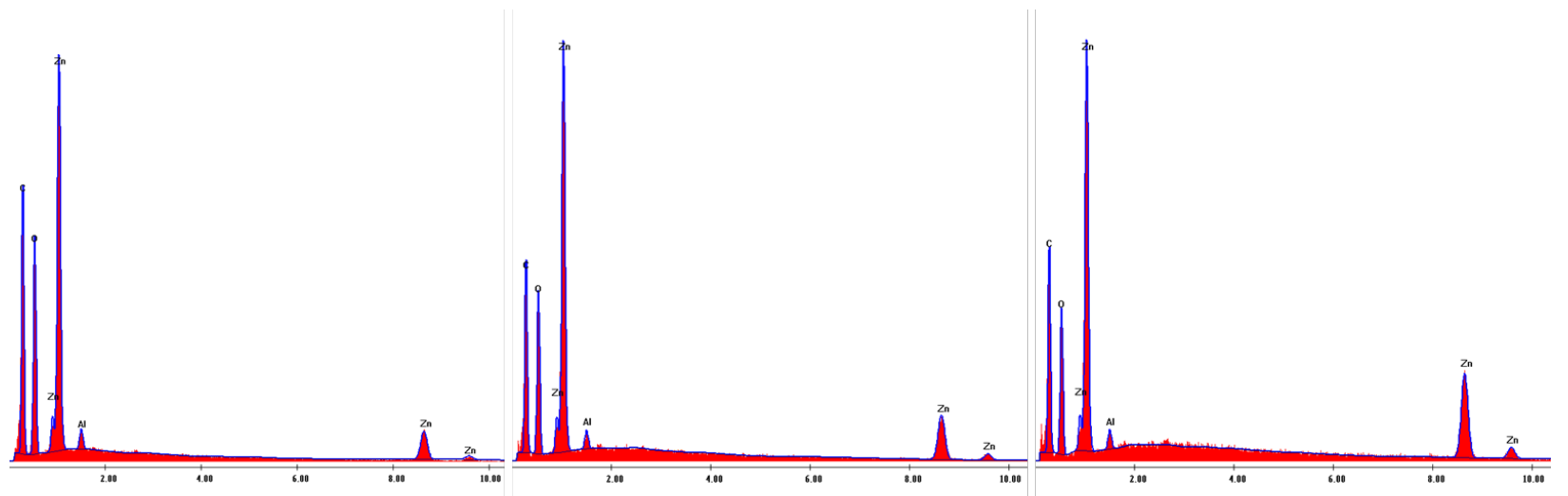

(a)

(b)

(c)

Figure S31. EDS analysis of Zn-MOF-74 (figure S30a, $100 \mu \mathrm{m}$ ). 


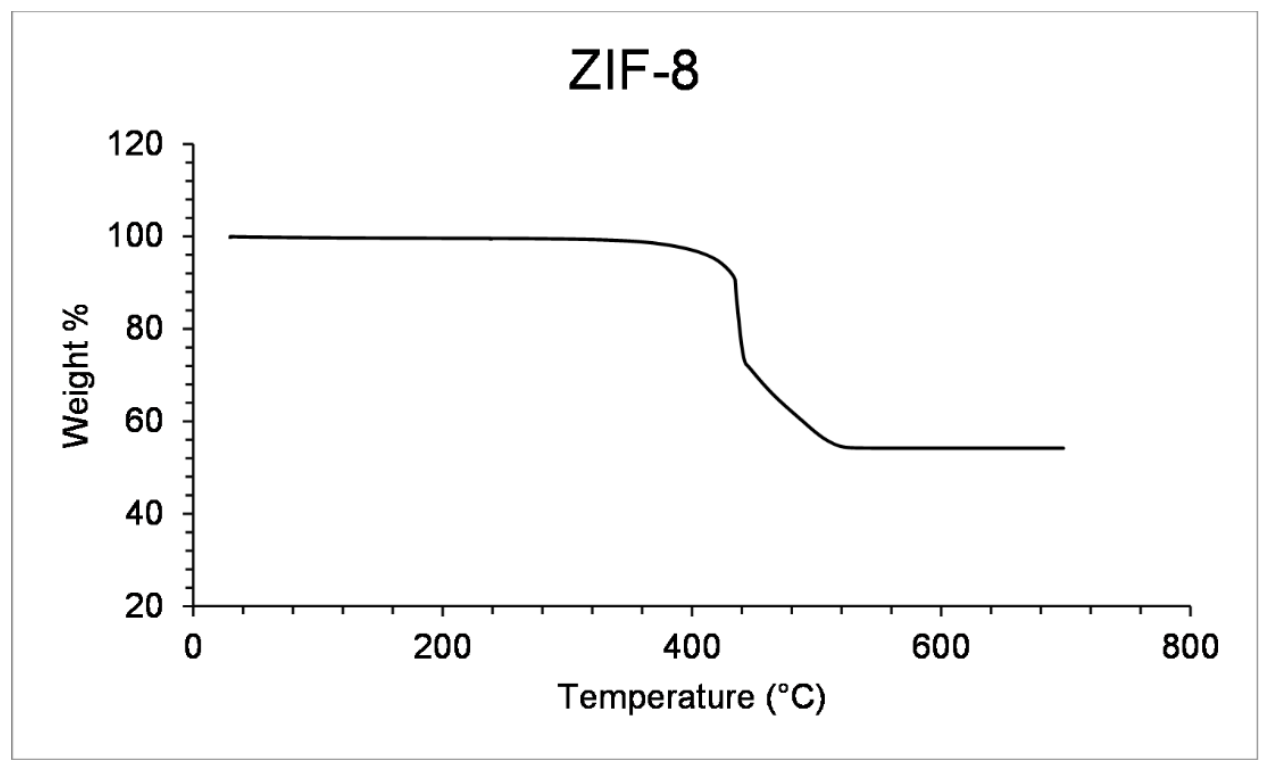

Figure S32. TGA analysis of ZIF-8.

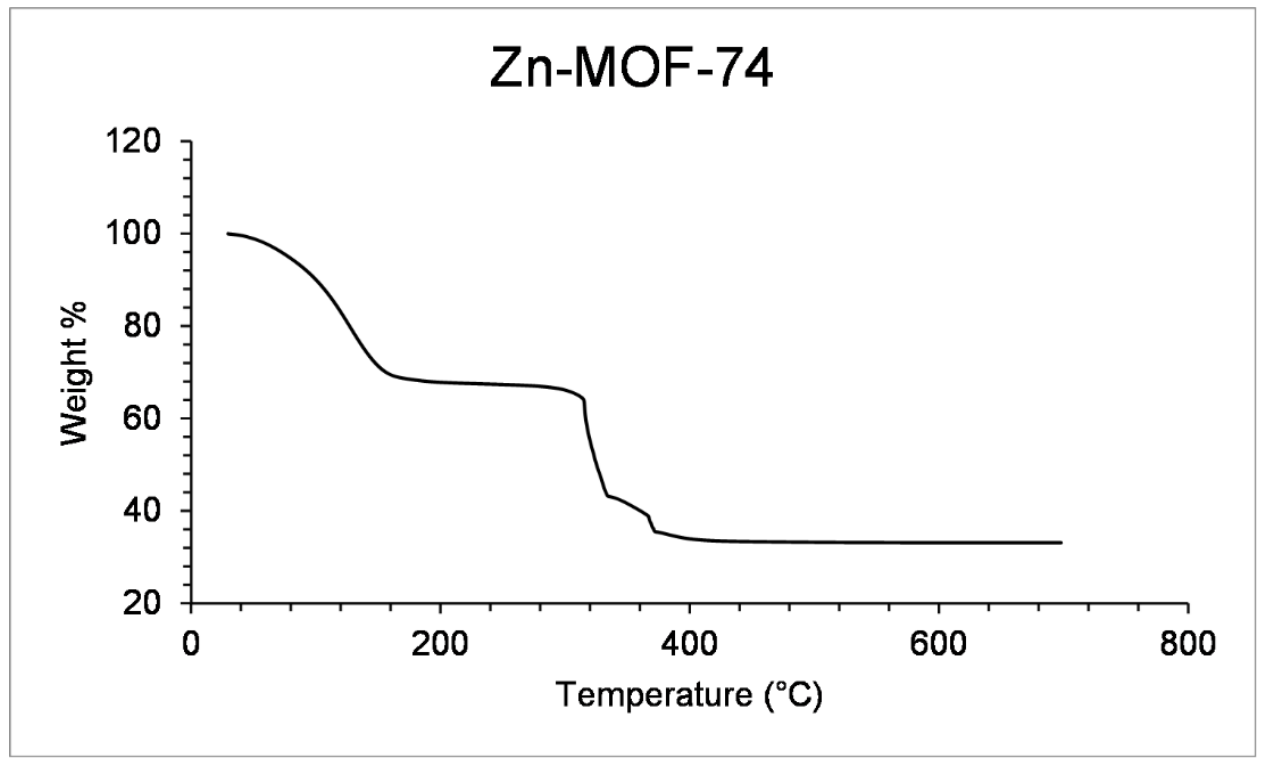

Figure S33. TGA analysis of Zn-MOF-74. 


\section{S8: References}

(1) Bloembergen, N.; Purcell, E. M.; Pound, R. v. Relaxation Effects in Nuclear Magnetic Resonance Absorption. Phys. Rev. 1948, 73 (7), 679-712. https://doi.org/10.1103/PhysRev.73.679.

(2) Macrae, C. F.; Sovago, I.; Cottrell, S. J.; Galek, P. T. A.; McCabe, P.; Pidcock, E.; Platings, M.; Shields, G. P.; Stevens, J. S.; Towler, M.; Wood, P. A.; IUCr. Mercury 4.0: From Visualization to Analysis, Design and Prediction. J. Appl. Cryst. 2020, 53, 226-235.

https://doi.org/10.1107/S1600576719014092. 